\title{
7 Anti-Israelismus als moderne Formvariante des Verbal-Antisemitismus: Die moderne Konzeptualisierung des kollektiven Juden
}

„Warum die schwarze Antwort des Hasses auf dein Dasein, Israel?“ (Sachs 1961: 100)

\subsection{Israel-Kritik versus Anti-Israelismus: Zwei verschiedene Sprachhandlungen}

\subsubsection{Zur Problematik}

Israel, das wichtigste Symbol jüdischen Lebens und Überlebens, ist für Antisemiten eine ungeheure Provokation und steht daher seit seiner Gründung im Fokus (rechts- und links)extremistischer Diffamierungskampagnen und Hetzpropaganda. Seit einigen Jahren sind aber auch zunehmend im öffentlichen Kommunikationsraum - unabhängig von politischer oder ideologischer Ausrichtung ${ }^{1}$ - Brachialverbalismen gegenüber Israel zu verzeichnen, die die Grenzen von legitimer Kritik und problematisierender Reflexion überschreiten und judenfeindliches Gedankengut (teils bewusst und kalkuliert, teils aber auch gedankenlos und nicht-intentional) in die Mitte der Gesellschaft tragen und das Sagbarkeitsfeld für Antisemitismen erweitern, ohne dass hinreichend Widerstand dagegen geleistet wird. Es kommt z. B. häufig (auch im massenmedialen Kommunikationsraum) zu unangemessenen Referenzialisierungen mittels NS-Vergleichen wie Nazi-Methoden oder Staatsterror wie im Dritten Reich und Phrasen wie rassistischer Apartheidstaat oder terroristisches Unrechtsregime. Wie massiv solche Äußerungsformen die öffentliche Meinung und das kollektive Bewusstsein beeinflussen, zeigen diverse Umfragen, die belegen, wie verbreitet die negative Gesamteinschätzung des Staates Israel in der Bevölkerung mittlerweile ist. So wurde Israel von 65 Prozent der Befragten in Deutschland 2003 als „größte Gefahr für den Weltfrieden“ gesehen (EC 2003). Im Januar 2007 waren drei von zehn befragten Deutschen laut einer Erhebung der Bertelsmann Stiftung der Meinung, dass Israel „einen Vernichtungskrieg gegen die Palästinenser“ führe und dass das, „was der Staat Israel mit den Palästinensern macht“, nichts anderes sei als das, „was die Nazis im Dritten Reich mit den Juden gemacht haben“ (Bertelsmann 2009).

1 Mitglieder der Partei Die Linke haben ein besonderes Problem mit dieser Form der verbalen Grenzüberschreitungen gegenüber Israel (s. Salzborn/Voigt 2011; vgl. auch Kloke ${ }^{2} 1994$ und 2010 sowie Haury 2001 und 2007 zum Antisemitismus bei Linken). 
Bei einer 2012 vom Stern in Auftrag gegebenen Forsa-Umfrage waren 70 Prozent der Befragten der Meinung, „Israel verfolge seine Interessen ohne Rücksicht auf andere Völker“. 59 Prozent beurteilten das Land als „aggressiv“ und 13 Prozent sprachen dem Staat sogar das Existenzrecht ab (Weber 2012). Diese Ergebnisse sind als das unmittelbare Resultat jahrelanger Diffamierungskampagnen gegenüber Israel sowie der zum Teil einseitigen, emotionalen Berichterstattung zum Nahostkonflikt in den Medien zu bewerten.

Eine damit verbundene Frage, die bereits seit Jahren nicht nur in der Antisemitismusforschung, sondern vor allem auch in der Gesellschaft aus gegebenen Anlässen ${ }^{2}$ heftig und kontrovers diskutiert, aber bislang wissenschaftlich noch nicht präzise genug und nachvollziehbar beantwortet wurde, betrifft die Abgrenzung von Israel-Kritik (als kommunikativ legitimer Meinungsäußerung) und Anti-Israelismus (als einer aktuellen Formvariante von Judenfeindschaft). Im 21. Jahrhundert ist die als Israel-Kritik deklarierte, tatsächlich aber antisemitisch fundierte Umwegkommunikation, ${ }^{3}$ die auf Israel referiert, aber Juden allgemein meint, die dominante Verbalisierungsmanifestation für die Artikulation und Verbreitung von judenfeindlichem Gedankengut. Israel wird mittels der Sprache verteufelt und an den Pranger gestellt, und es hat sich so (unter Rekurs auf alte judeophobe Stereotype) über die letzten Jahre ein anti-israelisches Zerrbild etabliert. Gesellschaftlich problematisch an dieser Sachlage ist dabei vor allem, dass es nicht nur kein ausgeprägtes Problembewusstsein für die Gefahren eines solchen (Stereotype transportierenden und Ressentiments verstärkenden) Sprachgebrauchs gibt, sondern dass auch reflexartig Verteidigungsmechanismen für ihn einsetzen, die eine gesamtgesellschaftliche Kritik und Zurückweisung verhindern. Die Versuche der Wissenschaft, die Brisanz bestimmter Kommunikationsformen und Sprachgebrauchsmuster bei diesem Thema aufzuzeigen, stoßen oft sofort auf eine automatische, emotionale Abwehrhaltung bei vielen Deutschen. Von Äußerungen wie Das ist eine Gleichschaltungspolitik! bis Wir sollen alle mundtot gemacht werden! reicht die Palette der Abwehrkommunikation, die auch von Vertretern der sogenannten Eliten(institutionen) benutzt wird. Die prinzipielle Verweigerung vieler Menschen, sich auf eine seriöse, an Fakten orien-

2 Im April 2012 z. B. anlässlich des israelfeindlichen Gedichts von Günter Grass, dessen Publikation in mehreren Zeitungen der Mainstreampresse zu einer heftigen Debatte führte.

3 Da der offene Antisemitismus seit 1945 verpönt ist und sanktioniert wird, hat sich diese Variante der impliziten Verbalisierungsform etabliert (s. Kap. 4.4). Die Sprachproduzenten können sich stets auf die Schutzbehauptung zurückziehen, sie seien keineswegs antisemitisch eingestellt, sondern würden lediglich Kritik an Israel üben. Teilweise handelt es sich allerdings nicht um einen „kommunikativen Umweg“, sondern um eine Doppel-Referenz-Kommunikation, insofern, als zugleich Juden und der Staat Israel angegriffen werden (s. die nachfolgenden Beispiele in Kap. 7.2). 
tierte Diskussion einzulassen oder wenigstens Zweifel an der unangemessenen Form bestimmter Sprechhandlungen zuzulassen, erschwert eine sachliche Auseinandersetzung. Die nach den Verbrechen der NS-Zeit entwickelten Maximen von „Nie wieder!“ und „Wehret den Anfängen!“ in Bezug auf Stereotypkodierung sowie das Bewusstsein für die Gefahren und möglichen Auswirkungen eines auf drastische Feindbildrhetorik reduzierten Sprachgebrauchs scheint dabei auch bei gebildeten Menschen, die entsprechende Äußerungen als „Meinungsfreiheit““4 und „individuellen Einstellungsausdruck“ verharmlosen oder sogar verteidigen, komplett ausgeblendet zu sein.

In diesem Zusammenhang ergeben sich zwei Fragen, die seit einigen Jahren fast turnusmäßig immer wieder (auch in den Massenmedien, die hier zum Teil in Bezug auf kritische Reflexion und Aufklärungsfunktion versagen $)^{5}$ aufs Neue gestellt werden: erstens, ob Kritik an Israel bzw. israelischer Politik prinzipiell und per se als judenfeindlich oder zumindest brisant eingestuft werden muss, und zweitens, wann eine israel-kritische Äußerung in Wahrheit nur eine verschleierte Form von Antisemitismus ist. Die erste, im öffentlichen Diskussionsraum bereits unzählige Male gestellte Frage, die eigentlich völlig überflüssig ist, da sie längst schon beantwortet wurde und durch die Kommunikationspraxis widerlegt ist, lässt sich einfach, unzweideutig und ohne jede weitere Erläuterung beantworten: Selbstverständlich ist (auch eine unter Umständen sehr scharfe) Kritik an bestimmten Entscheidungen israelischer Regierungsvertreter oder extremer nationalistischer Gruppierungen im Land oder an Aktionen des israelischen Militärs kein Antisemitismus, sondern legitimer Ausdruck von politischer Auseinandersetzung und problemorientierter Kommunikation. Entsprechend gibt es, wie bei jedem anderen Land der Erde auch, Vieles, was aus der Innen- ${ }^{6}$ und Außenperspektive kritisch angesprochen wird. Dies geschieht kontinuierlich

4 Vgl. hierzu auch Bergmann/Heitmeyer (2005b: 229 f.).

5 Vgl. etwa Schlagzeilen wie „Darf man Israel kritisieren?“ oder „Wie viel Kritik an Israel ist Deutschen erlaubt?" sowie diverse ähnliche Varianten, die in Printmedien, Rundfunk- und Fernsehsendungen regelmäßig benutzt werden. Solche Sprachstrukturen unterstellen aufgrund ihrer semantischen Information, es gebe ein Meinungsdiktat und eine Tabuisierung. Dadurch wird de facto etwas nicht Existierendes sprachlich geradezu heraufbeschworen. Ähnlich verhält es sich mit der Metapher Antisemitismuskeule, die impliziert, Israel-Kritikern würde stets der Antisemitismusvorwurf gemacht, obgleich dieser Vorwurf immer nur dann erhoben wird, wenn tatsächlich eine antisemitische Äußerung produziert wurde. Fragen und Behauptungen dieser Art werden keineswegs aus naiver Dummheit oder Unkenntnis geäußert, vielmehr dienen sie den Medien als populistische Aufmerksamkeitsverstärker. Antisemiten inszenieren ihre Kritik an Israel dagegen kalkuliert als Tabubruch, um sich gegen den Vorwurf des Antisemitismus immun zu machen. Die Kritik dient so der Ablenkung von ihrer judenfeindlichen Einstellung und zugleich der Delegitimierung ihrer Kritiker.

6 Einige der schärfsten Kritiker israelischer Siedlungs- und Militärpolitik sind Israelis. 
in allen deutschen (und westlichen) Massenmedien, insbesondere in Bezug auf den noch nicht gelösten Konflikt mit den Palästinensern, und bislang ist auch noch nie einem seriösen Kritiker israelischer Siedlungspolitik oder Militäraktionen vorgeworfen worden, es handele sich bei seinen Äußerungen um Antisemitismus. Dieser Vorwurf wird immer nur dann erhoben, wenn es sich um antiisraelische Äußerungen handelt, die antisemitische Stereotype vermitteln und/ oder Brachialverbalismen enthalten, die faktisch falsche Informationen vermitteln ${ }^{7}$ und/oder das Potenzial haben, eine judenfeindliche Stimmung zu erzeugen. Doch hält sich hartnäckig, fast obsessiv, trotz der andersgearteten Realität und aller faktischen Widerlegungen, das Klischee, Kritik an Israel sei in Deutschland aufgrund der NS-Geschichte ein Tabu (s. zu diesem Stereotyp bereits Kap. 5). Die Behauptung, es gebe ein Kritiktabu, bedient dabei selbst ein tradiertes judeophobes Klischee, das seit dem 19. Jahrhundert existiert und auf der Konzeptualisierung basiert, es gebe eine jüdisch bestimmte Presse, die in Deutschland den Ton angibt. Seine Artikulation stützt somit die verschwörungstheoretisch determinierte Position der Sprachproduzenten, die sich zugleich als Verfechter der Meinungsfreiheit gerieren können (vgl. die Varianten von „Was gesagt werden muss“ in Kap. 5 sowie Kap. 11.2 und 11.4 zu den Legitimierungs- und Rechtfertigungsstrategien).

$$
\begin{aligned}
& \text { „bei keinem anderen staat wäre das notwendig, aber wenn man israel } \\
& \text { in deutschland kritisiert, muss man wohl hinzufügen: ich bin kein anti- } \\
& \text { semit, kein rechtsradikaler, ja ich habe unter meinen bekannten auch } \\
& \text { juden und bin ein bewunderer der kultur der europäischen juden. da } \\
& \text { man ja aber in israel die zynische gleichung aufgestellt hatte: kritik an } \\
& \text { israel = antisemitismus, wird Sie das vermutlich wenig beeindrucken. } \\
& \text { nun zum thema: ich betrachte das vorgehen israels gegen die palästi- } \\
& \text { nenser mit entsetzen und abscheu.“ [IBD_11.07.2006_Sch_001] }
\end{aligned}
$$

7 So stellte z. B. Günter Grass in seinem Text den atomaren Konflikt zwischen dem Iran und Israel völlig realitätsverzerrend dar, indem er Israel unterstellte, einen Angriff gegen das iranische Volk zu planen, während die realen Vernichtungsdrohungen des iranischen Präsidenten Ahmadinedschad, der als „Maulheld“ bezeichnet wurde, gegenüber Israel marginalisiert wurden. Das von Grass bereits im Titel „Was gesagt werden muss“ unterstellte Tabu der Israel-Kritik stellte ebenfalls eine drastische, stereotypbasierte De-Realisierung dar. Dennoch nahm beispielsweise der Präsident der Akademie der Künste Grass folgendermaßen in Schutz: „Man muss ein klares Wort sagen dürfen, ohne als Israel-Feind denunziert zu werden“, Grass habe „das Recht auf Meinungsfreiheit auf seiner Seite“ und nur „seiner Sorge Ausdruck verliehen "(Klaus Staeck am 05.04.12 in der in Halle erscheinenden Mitteldeutschen Zeitung). Der Schriftsteller Rolf Hochhuth trat dagegen aus Protest gegen die anlässlich der Grass-Debatte entfachten Diskussionen aus der Akademie aus. 
Dass (sogar im Gegenteil) kein Staat der Welt so unverhältnismäßig oft und heftig kritisiert wird wie Israel, ${ }^{8}$ wird in Zuschriften wie (1) ignoriert oder geleugnet. Auffällig und signifikant ist in diesem Zusammenhang, dass dieses angebliche Meinungsdiktat stets nur von Personen unterstellt wird, deren Äußerungen nicht als israel-kritisch, sondern als verbal-antisemitisch einzustufen sind. Damit kommen wir zur zweiten Frage, die oben angesprochen wurde, der Abgrenzung und Unterscheidung der beiden Sprechhandlungstypen Israel-Kritik und Anti-Israelismus. ${ }^{9}$ Allen bislang in der öffentlichen Diskussion vorgebrachten Bedenken und Negierungen zum Trotz ist hier eine klare Unterscheidung möglich: Beide kommunikativen Phänomene können mittels kognitions- und sprachwissenschaftlicher Kriterien präzise voneinander abgegrenzt werden. Die Negierungen in Bezug auf eine solche Abgrenzungsmöglichkeit zeigen nur das Bedürfnis von Antisemiten, sich die öffentlich artikulierbaren Formen der Judeophobie nicht nehmen lassen zu wollen. Je mehr Argumente und Fakten aus der Forschung kommen, die die antisemitische Dimension des Anti-Israelismus transparent machen, desto größer und erbitterter ist der Widerstand der selbsterklärten Israel-Kritiker. Selbst klar als verbal-antisemitisch erkennbare Äußerungen werden als ,,anti-antisemitisch“ ausgegeben. Zugleich verteidigen auch viele Politiker und Journalisten oft Personen, die sich dem Vorwurf des Antisemitismus ausgesetzt sehen: Sie seien „nur kritisch“ oder hätten „nur ungeschickt formuliert“. Diese Fehldeutungen und Marginalisierungen entstehen teils aus dem Mangel an Kenntnis über die tradierten und aktuellen Ausdrucksvarianten des Verbal-Antisemitismus und teils aus der Unterschätzung des Potenzials der sprachlichen Dämonisierungsrhetorik.

Nicht dass Kritik geübt wird, sondern wie diese argumentativ begründet und sprachlich formuliert wird, ist für diese Diskussion entscheidend. Wenn Israel als Projektionsfläche für antisemitische Ressentiments dient und tradierte antijüdische Stereotype und Argumente benutzt werden, um den Staat Israel gene-

8 Vgl. hierzu u.a. Behrens (2003), Jäger et al. (2003), Schapira/Hafner (2010). Kontrastive Untersuchungen zur massenmedialen Krisen- und Konfliktberichterstattung zeigen, dass die Nahostberichterstattung in Deutschland einen wesentlich breiteren Raum einnimmt als z. B. die Berichterstattung zum Indien-Pakistan-Konflikt oder zu Nordkorea, obgleich bei diesen Konflikten de facto das Gefahrenpotenzial ein viel Höheres ist. Entsprechend ist es mit der Verteilung der Internet-Kommentare. Das Emotionspotenzial ist zudem bei israelkritischen Texten wesentlich höher (s. Schwarz-Friesel 2007: 228). Es kommt insgesamt zu mehr Schuldzuweisungen und monokausalen Erklärungen sowie pauschalen Opfer-TäterFestlegungen.

9 Antizionismus ist eine dritte Variante. Da aber oft Anti-Israelismus und Antizionismus untrennbar aneinander gekoppelt sind und sprachlich zumeist keine Differenzierung vorgenommen wird, subsumieren wir diese Variante unter Anti-Israelismus. Vgl. hierzu ausführlich und differenzierter u. a. Kloke (21994, 2010), Claussen (1995), Mertens (1995), Orland (1999) und Haury (2001). 
rell zu diskreditieren, wenn seine jüdischen Bürger kollektiv dämonisiert werden und seine Existenzberechtigung als jüdischer Staat in Frage gestellt wird, wenn ein irreales Feindbild von Israel konstruiert wird, dann liegt keine Israel-Kritik, sondern verbaler Antisemitismus in der Formvariante des Anti-Israelismus vor. Dabei lassen sich verschiedene Typen judenfeindlicher Verbalisierungen expliziter wie impliziter Art voneinander abgrenzen, die wir im Folgenden nach ihren formalen und semantischen Charakteristika erläutern.

\subsubsection{Israel-Kritik als kommunikative Handlung}

Es ist hilfreich, sich zunächst sprechaktorientiert vor Augen zu führen, was für eine kommunikative Handlung Kritik ist, welche Funktion sie erfüllt und auf welchen Voraussetzungen sie basiert. Jemand, der etwas bzw. jemanden kritisiert, gibt ein Urteil über das Verhalten und/oder die Handlung eines anderen ab. Das Kritisierte wird dabei als negativ bewertet. Der Kritiker muss glauben, dass dem Kritisierten dies nicht bewusst ist (denn sonst wäre der kommunikative Akt an sich überflüssig) und dass das Kritisierte in der Zukunft verbessert oder behoben werden kann (sonst wäre der Sprechakt sinnlos; vgl. absurde und irrationale Kritik wie \#Ich kritisiere, dass du sterblich bist oder \#Ich kritisiere, dass du geboren wurdest). ${ }^{10}$ Der Sprachproduzent muss zudem über hinreichende Kenntnisse verfügen, um von der Existenz und der Wahrheit des als negativ Beurteilten überzeugt zu sein (denn sonst handelt es sich um reine Spekulation, Verleumdung oder Lüge). Die Funktion des Sprechaktes Kritisieren ist es zum einen, sich auf die Wahrheit des Ausgesagten festzulegen (damit ist Kritisieren ein Repräsentativ) und zum anderen, den Adressaten durch den Hinweis so zu beeinflussen, dass dieser den negativ bewerteten Aspekt erkennt und verändert (damit ist Kritisieren auch ein Direktiv mit Appellfunktion). Die intendierte Reaktion, die der Kritiker beabsichtigt, ist, ein Problembewusstsein beim Adressaten zu erreichen (und weiterhin, diesen dadurch zu einem Umdenken bzw. einer anderen Handlungsweise zu bewegen). Um dies erreichen zu können, muss der Kritiker nachvollziehbare, argumentativ begründete und sachbezogene Urteile vermitteln, die den Kritisierten überzeugen können. Kritik unterscheidet sich dadurch maßgeblich von anderen kommunikativen Handlungen wie z. B. Beschimpfen, Beleidigen, Verunglimpfen, Verleumden und Diskriminieren (die sich dadurch auszeichnen, dass die Ehre des Adressaten angegriffen, seine Würde tangiert und/oder seine Person als Ganzes entwertet wird, s. hierzu Kap.10). Entspre-

10 Das Symbol \# wird in linguistischen Beispielanalysen benutzt, um anzuzeigen, dass eine semantisch-konzeptuelle Implausibilität oder Inkompatibilität vorliegt. 
chend gilt auch eine Sprechhandlung wie Ich kritisiere, dass du widerliches Wesen existierst nicht als Kritik, sondern als (drastische) persönliche Beleidigung und Ehrabschneidung. Subsumiert man Kritik unter die persuasiven, d. h. intentional Adressaten beeinflussenden Sprachhandlungen, ist eine Voraussetzung für den potenziellen Erfolg, die negative Bewertung nachvollziehbar und begründet (sowie die Alternative als durchführbar) für den Adressaten darzustellen (vgl. Schwarz-Friesel et al. 2012). Dadurch ist Kritik eine kommunikative Handlung, die realitätsbezogen, wahrheits- und problemorientiert Bewertungen vermittelt, um eine Veränderung(smöglichkeit) aufzuzeigen, die als Verbesserung bzw. Problemlösung zu erachten ist.

Dass Kritik in genau diesem Sinne auch in politischen Krisensituationen geübt werden kann und selbstverständlich nicht jede Kritik am Staat Israel per se antisemitisch ist, lässt sich am besten an konkreten Texten zeigen. Obgleich bei den E-Mails und Briefen an den ZJD und die IBD israelfeindliche und judeophobe Schreiben dominieren, die aufgrund von Form und Inhalt als verbal-antisemitisch zu beurteilen sind, gibt es auch eine Reihe von Texten, die tatsächlich nur Kritik und/oder Sorge artikulieren, ohne in antisemitische Argumentationsmuster $\mathrm{zu}$ verfallen oder radikale, destruktive Vorschläge zu unterbreiten und ohne brisante NS-Vokabeln und pejorative Entwertungslexeme zu benutzen. Anhand zweier solcher Texte aus unserem Korpus soll exemplarisch gezeigt werden, wann ein Text als Exemplar der Textsorte „Israel-Kritik“ zu klassifizieren ist.

Wenn Kritik an einzelnen politischen, militärischen oder sozialen Gegebenheiten (wie Siedlungsbau, Kontrollen an Grenzen, Einsatz von verpönten Waffen oder der Einfluss der Orthodoxen auf zivile Einrichtungen) geübt wird, so ist dies der legitime Ausdruck von Meinungsfreiheit und die Artikulation von Verantwortungsbewusstsein. Eine solche Kritik wird z. B. in (2), der E-Mail von einem Ehepaar aus Bad Driburg, vorgebracht:

(2) „heute morgen hörten meine Frau und ich im WDR 5 über den Einsatz von 4 Mio Streubomben während des Libanonkrieges von Seiten Ihres Landes im vergangenen Jahr. Es wurde deutlich, dass durch sie immer noch und für unbegrenzte Zeit Personen zu Schaden kommen. Wir sind erstaunt und befremdet darüber, dass Israel den dort arbeitenden Minenräumern die Abwurfkoordinaten nicht zur Verfügung stellt. Wir bitten Sie herzlich, Excellenz, Ihren Einfluß für die Herausgabe der Daten bei Ihrer Regierung einzusetzen.“[IBD_14.08.2007_Rie_001]

In (2) wird ein singulärer Sachverhalt (nämlich der Einsatz von Streubomben) zum Anlass genommen, eine kritische Stellungnahme dazu zu artikulieren und einen Appell an den Botschafter als Vertreter Israels in Deutschland zu formulie- 
ren. Nichts an dieser E-Mail ist in irgendeiner Weise explizit oder implizit judenfeindlich oder anti-israelisch. Die negative Beurteilung („dass durch sie immer noch und für unbegrenzte Zeit Personen zu Schaden kommen“) ist sachorientiert, an ethischen Prinzipien ausgerichtet und kognitiv wie emotional nachvollziehbar. Die Kritik wurde an die Israelische Botschaft als Vertretung des Landes Israel gesendet, ohne deshalb generalisierend das Existenzrecht Israels oder Israels Recht auf Selbstverteidigung in Frage zu stellen. Die Einstellungsbekundung mittels der Adverbien „erstaunt“ und „befremdet“ verdeutlicht, dass bei den Textproduzenten keine Konzeptualisierung von ISRAEL ALS AGGRESSOR vorliegt. Es finden sich auch keine sprachlichen Ausdrücke auf der Satz- und Textebene, die für eine derartige Vorstellung sprächen oder auf eine kollektive Negativbewertung und/oder Dämonisierung Israels schließen ließen. Argumentativ ist die Zuschrift durch Kohärenz und Widerspruchsfreiheit gekennzeichnet, denn Schreibanlass und Textinhalt stimmen überein und die Argumentation ist klar und folgerichtig aufgebaut: Es erfolgt die Angabe des Anlasses für die Kritik mit genauem Quellenverweis, eine Radiosendung des WDR5, und die Wiedergabe des Sendungsinhaltes, der den Auslöser für das Schreiben darstellt. Auf Grundlage dieser Fakten wird das Verhalten Israels kritisiert und über einen direktiven Sprechakt die Handlungsaufforderung, der Botschafter möge zur Verbesserung des kritikwürdigen Umstandes beitragen, zum Ausdruck gebracht.

In anderen E-Mails an die Botschaft werden $\mathrm{u}$. a. Siedlungsbau und gezielte Tötungen als „kontraproduktiv für den Friedensprozess“, als „,bedenklich“ oder „schädlich für das Miteinander“ bezeichnet. Kritiker, denen bewusst ist, wie problematisch es angesichts der deutschen NS-Vergangenheit gerade für Deutsche ist, jüdischen Israelis Ratschläge zu erteilen, benutzen entsprechend sogenannte Heckenausdrücke ${ }^{11}$ wie ich weiß natürlich nicht sicher, ob oder irgendwie oder sicher können Sie das besser beurteilen, dennoch (vgl. Beispiel (3)).

Auch Schreiben, die sich nicht nur auf einzelne Aspekte konzentrieren, sondern die allgemeine Rolle der israelischen Regierung im gesamten Nahostkonflikt kritisch ansprechen, sind nicht notwendigerweise antisemitisch.

„Es ist ganz schwer für die Menschen hier in Deutschland, die Situation im Nahen Osten richtig ein zu schätzen, zumal die Berichterstattung einseitig ist und Dinge falsch darstellt, weil sie aus dem Kontext gerissen

11 Heckenausdrücke (engl. hedge ‘ausweichen, sich nicht festlegen') sind Wörter und Phrasen, die benutzt werden, wenn dem Sprecher/Schreiber klar ist, dass er etwas Schwieriges ausdrückt bzw. dass er vorsichtig formulieren sollte (vgl. z. B. Schwitalla ${ }^{3} 2006:$ 155). In kritischen Diskursen indizieren diese Ausdrücke Höflichkeit und Rücksichtnahme auf den Adressaten, zeigen Respekt und ernsthaftes Interesse an einer Verständigung. 
sind. Bitte gestatten Sie mir trotzdem die Äußerung einiger Gedanken $\mathrm{zu}$ obigen Konflikten. [...] Die Lebenssituation in Israel erfordert wohl besondere Maßnahmen; und ich kann möglicherweise nicht nach vollziehen, wie schwer und unsicher ein Leben in Ihrem Land ist. Trotzdem komme ich mit der Politik Israels nicht zurecht. Und ich bitte Sie von Herzen, auf Ihre Regierung ein zu wirken, daß sie andere Wege als den Krieg sucht und die Friedensgespräche fortsetzt bzw. intensiviert und Gespräche mit der Autonomiebehörde im Gazastreifen aufnimmt. Ich bedanke mich bei Ihnen, daß Sie meinen Ausführungen Aufmerksamkeit geschenkt haben.“ [IBD_01.09.2006_Die_001]

Wenngleich die Verfasserin von (3), eine Dame aus Frankfurt am Main, offensichtlich generell die israelische Regierung und nicht auch die Palästinenserbehörde als hauptverantwortlich für die kriegerischen Auseinandersetzungen im Nahostkonflikt sieht und damit eine monoperspektivische Sichtweise einnimmt, so verzichtet sie doch auf Verbal-Aggressivitäten und/oder extreme Schuldzuweisungen sowie allgemeine Diskreditierungen. Auch findet sich kein einziger Hinweis auf judeophobe Stereotypkodierungen. Sie thematisiert zudem (selbstund medienkritisch) ihren limitierten Kenntnisstand aufgrund fehlender Selbsterfahrungen und räumt damit ihre eingeschränkte Sicht und Urteilsfähigkeit als Kritisierende ${ }^{12}$ ein.

Die Kritik an der Politik Israels ist in (2) und (3) deutlich problemlösungsorientiert. Es zeigen sich keinerlei Spuren einer antisemitischen oder israelfeindlichen Einstellung in den Texten. Entsprechend finden sich auch keine Beteuerungen, man sei kein Antisemit. Solche Leugnungsstrategien finden sich fast ausschließlich bei Sprachproduzenten, die Verbal-Antisemitismen kommunizieren ${ }^{13}$ und im Bewusstsein der Brisanz ihrer eigenen Äußerungen durch die Vorwegnahme

12 Diese selbstkritische und die Nahostberichterstattung in ihrer meinungsformenden, subjektiven Dimension reflektierende Ein- und Umsicht lässt die Mehrzahl der anderen (zum Teil sehr gebildeten) E-Mail-Schreiber vermissen. Israel-kritische Medienberichte werden entweder distanzlos übernommen oder zum Anlass für exzessive Anschuldigungen und Beleidigungen genommen.

13 Vgl. zur Definition von Verbal-Antisemitismus Kap. 3. Es ist keineswegs immer nur geheuchelte Unkenntnis und konzeptueller Judenhass, die zur Produktion von VerbalAntisemitismen führen. Mangelndes Hintergrundwissen und fehlendes Problembewusstsein für die Brisanz bestimmter Sprachgebrauchsmuster können ebenfalls der Grund sein. Ob die Äußerungen mit dem Bewusstsein, judenfeindlich eingestellt zu sein, und dem Ziel, Juden zu diskriminieren, artikuliert werden, spielt aber keine wesentliche Rolle. Auch nicht-intentionale Verbal-Antisemitismen tragen maßgeblich dazu bei, dass judenfeindliche Stereotype über die Kommunikation vermittelt werden. 
des antizipierten Vorwurfs diesen zu entkräften suchen. Dass beide Verfasser ihre Schreiben nicht, wie so viele andere, (auch) an den ZJD, sondern ausschließlich an die IBD senden, ist ebenfalls ein wichtiger Indikator: Nur Sprachproduzenten, die eine konzeptuelle Gleichsetzung von jüdischen und israelischen Belangen sowie eine kollektive, gesamtjüdische Schuld und Verantwortung in Bezug auf den Nahostkonflikt unterstellen, adressieren israel-kritische Schreiben auch an den ZJD. Auch wird der konkrete Adressat, d. h. der Botschafter des Staates Israel, in seiner tatsächlichen Funktion angesprochen, an den ein bestimmtes Anliegen herangetragen wird, ohne dass es zu persönlichen Entwertungen oder Diskriminierungen kommt. Die Einhaltung sprachlicher Höflichkeitskonventionen ${ }^{14}$ belegt zudem die Aufrechterhaltung einer auf sozialer Akzeptanz aller Kommunizierenden basierenden und um Kooperation bemühten Kommunikation.

Demgegenüber steht eine große Anzahl von Schreiben, deren Verfasser sich zwar als israel-kritisch und anti-antisemitisch bezeichnen, die tatsächlich aber antisemitisches Gedankengut artikulieren. Kognitionslinguistische Analysen können die spezifischen Charakteristika solcher Äußerungen transparent machen und damit eine klare Abgrenzung von israel-kritischen und antisemitischen Sprachgebrauchsmustern ${ }^{15}$ vornehmen.

\subsubsection{Anti-Israelismus als „Ismus“ und verbale Gewalt}

Der Forschung liegen bereits einige Abhandlungen vor, die sich mit antisemitischen Äußerungen, die im Gewand der Israel-Kritik ${ }^{16}$ vorgebracht werden, beschäftigen und Merkmale genannt haben (ohne dabei jedoch Detail-Analysen vorzulegen), die typisch für anti-israelischen Antisemitismus sind. Am häufigsten werden hierbei die drei Ds genannt (s. u. a. Neugebauer 2003, Markovits 2004, Rensmann 2004: 88 f., Pfahl-Traughber 2007a): Dämonisierung (seman-

14 Sprachliche Höflichkeit ist ein Indikator dafür, dass die Sprachproduzenten den Adressaten als kommunikativen Partner sozial anerkennen und schätzen. Zu persuasiven Funktionen von Höflichkeit, Unhöflichkeit und Schein-Höflichkeit s. Malicke, in Arbeit. 15 Für Pfahl-Traughber (2007a: 50, 53) ist die Rekonstruktion und Benennung der „eigentlichen inhaltlichen Motive“ bzw. die „konkrete Motivation“ ausschlaggebend für die Abgrenzung von Israel-Kritik und Antisemitismus. Die tatsächliche Motivation eines Sprachproduzenten ist aber in der Praxis nicht oder nur höchst selten zu eruieren, sie spielt auch für die Klassifikation von Äußerungen als Verbal-Antisemitismen keine Rolle. Relevant sind hierbei ausschließlich die sprachlichen Kodierungsformen, die sich exakt beschreiben und aufgrund ihrer semantischen Eigenschaften als judenfeindlich erklären lassen. 16 Zu den eher allgemeinen, kontrovers geführten Diskussionen zu diesem Thema s. vor allem Rabinovici et al. (2004), Rauscher (2004), Kreis (2005), Zuckermann (2005). 
tische Entwertung), Delegitimierung (Aberkennung des Existenzrechts Israels) und Doppelstandard (die Beurteilung Israels mit einem besonderen Maßstab). Diese Schlagworte sind jedoch von ihrer Semantik her recht vage und müssen konkretisiert werden, um trennscharf, nachvollziehbar und verständlich zu sein. So hat sich das EUMC $^{17}$ auf die folgenden fünf ausbuchstabierten Indikatoren festgelegt, um angeben zu können, wann Israel-Kritik antisemitisch ist (zu den Indikatoren vgl. EUMC 2004: 229, Gessler 2004: 10, 15, Bunzl 2005: 278, Heyder et al. 2005: 146 f., Kloke 2005: 22, Schapira/Hafner 2006):

1. Wenn Israel sein Existenzrecht und/oder das Recht zur Selbstverteidigung abgesprochen wird.

2. Wenn an Israel im Vergleich zu anderen Ländern ein doppelter Standard angelegt wird.

3. Wenn mittels antisemitischer Floskeln, Symbole oder Bilder auf Israel oder Israelis referiert wird.

4. Wenn die israelische Politik oder Israelis mit dem Nationalsozialismus bzw. Personen aus dieser Zeit gleichgesetzt werden.

5. Wenn Juden weltweit für die Politik Israels verantwortlich gemacht werden.

Dieser Katalog muss, wie wir nachfolgend zeigen, erweitert und präzisiert werden. Inwiefern für die Einordnung einer Äußerung/eines Textes als antisemitisch nur ein Kriterium oder mehrere Indikatoren vorhanden sein müssen, ob es eine Wechselwirkung bzw. Interdependenz der Indikatoren gibt oder ob zu unterscheiden ist, wie explizit oder implizit ein Indikator oder mehrere realisiert werden, wird in diesem Kriterienkatalog ebenfalls nicht geklärt. ${ }^{18}$ Vor allem fehlen konkrete Beispiele, die verdeutlichen können, wie und in welchen Variationen Antisemitismus als Anti-Israelismus ausgedrückt wird bzw. werden kann. Anhand der folgenden Beispiele wird bereits deutlich, wie wichtig die Beantwortung dieser Fragen und die Erörterung konkreter Manifestationsvarianten sind.

Text (4) zeichnet sich dadurch aus, dass alle Indikatoren zusammen allein über die wortwörtliche Semantik festgestellt werden können:

17 Abkürzung für European Monitoring Centre on Racism and Xenophobia.

18 Lediglich bei Heyder et al. (2005: 146 f.) findet sich die Festlegung, dass Israel-Kritik antisemitisch ist, wenn auch nur eines der folgenden Kriterien erfüllt wird: die Aberkennung des Existenzrechtes Israels und des Rechtes auf Selbstverteidigung, das Vergleichen der israelischen Palästinenserpolitik mit der Judenverfolgung im Dritten Reich, die Beurteilung der israelischen Politik mit einem doppelten Standard, die Übertragung antisemitischer Stereotype auf den israelischen Staat. Vgl. auch Pulzer (2003: 96 ff.). 
(4) „Die Verbrechen des Staates auf gestohlenem Land: Israhell werden gesuehnt werden, davon koennt ihr Judenschweine ausgehen. [...] Glaubt ihr wirklich das man eurer KZ in Gaza nicht schon als solches erkannt hat? Ihr Schweine werdet haengen, brennen, vergast werden und das nach streng rechtstaatlichen Gesichtspunkten. Um den Frieden in der Welt zu garantieren muss der Jude verschwinden. Ihr kotzt uns an! Besonders dann wenn ihr glaubt uns was von Moral und Menschenrechten erzaehlen zu koennen. Eure US Juden haben die Welt-Finanz zerstoert. Buchenwald, Ausschwitz und Dachau sollten endlich wieder geoeffnet werden um den stinkenden Rest von euch zu erledigen. Wir haben keine Angst vor irgendwelchen Gesetzen oder juedischer Dumm Propaganda. Ein Judenfriedhof ist gerade gut genug um einen Muellhalde dort zu errichten. Verschwindet endlich aus Europa! Oder vergast euch selbst.“

[ZJD_Gaza2009_300/816_Mon_001]

Die Gaza-Krise wird zum Anlass genommen, eine judenfeindliche, hasserfüllte E-Mail an den Zentralrat der Juden in Deutschland zu senden. Explizit werden Israelis mit Juden (und Juden mit Israelis) durch Adressierung, Anrede und direkte Referenz gleichgesetzt und kollektiv mittels tradierter judeophober Floskeln dehumanisiert und dämonisiert, beleidigt und bedroht. Dicht hintereinander finden sich hier zahlreiche rassistische Stereotypzuweisungen mit Dehumanisierungs- und Dämonisierungssemantik (z. B. Juden als Tiere, Israel als Hölle) sowie verschwörungstheoretische Feindbildkonstruktionen (destruktive Beherrschung der Finanzwelt, Ausnutzung von Medienmacht, Fremdgruppenzuweisung etc.). Es werden diverse NS-Vergleiche gezogen, Israel wird als Staat delegitimiert, seine Gründung als widerrechtlich gewertet, und es wird von der übrigen Staatengemeinschaft als Verkörperung des Bösen ausgegrenzt und damit singulär verdammt. Negative Kollektiv-Attribuierungen und realitätsverzerrende, monokausale Schuldzuweisungen sind an verschwörungstheoretische Phantasien gekoppelt. Ein in sich konzeptuell und emotional geschlossenes antisemitisches Weltbild wird transparent.

Beispiel (5) dagegen kann anhand eines einzelnen Indikators als antisemitisch eingestuft werden, denn das alte antisemitische Stereotyp der BLUTLEGENDE (die Religion zwinge Juden, Blut zu trinken) wird explizit auf Israelis übertragen. ${ }^{19}$

19 Vgl. auch: „Eure Geschichte ist voll von Blut. Täter seid Ihr nicht Opfer.“ [IBD_20.07.2006_ano_008] 


$$
\begin{aligned}
& \text { „Was ist mit freilaufenden israelischen Faschisten und Mörder, die nicht } \\
& \text { nur 'Blut an ihren Händen klebt' sondern sich von menschlichem Blut } \\
& \text { ernähren [...].“ [IBD_28.06.2007_Ard_001] }
\end{aligned}
$$

Wie wir bereits bei den Verbalisierungen aktueller judenfeindlicher Stereotype gezeigt haben, gibt es aber auch wesentlich subtilere Ausdrucksformen, die nicht immer auf den ersten Blick sofort als antisemitisch erkannt werden. In Beispiel (6) ist ein Indikator für Antisemitismus vorhanden, nämlich die Übertragung des klassischen antisemitischen Stereotyps JUDEN SIND STÖRENFRIEDE auf Israel, jedoch ist dies nur über eine Implikatur zu erschließen.

„Israelis sind Störenfriede [...] Sie sollten aus der Geschichte gelernt haben und sich nicht darauf verlassen, dass Israelis alles dürfen“ [IBD_07.05.2006_Dro_001]

Über die Formulierung „Sie sollten aus der Geschichte gelernt haben“ wird implizit auf den Holocaust verwiesen und dadurch werden Israelis mit Juden gleichgesetzt. Über diese implizit vermittelte, durch Weltwissensaktivierungen $\mathrm{zu}$ verstehende Gleichsetzung wiederum entsteht eine zweite pejorative Beurteilung, die ein besonderes Ausmaß des angeblichen moralischen Versagens von Juden unterstellt (Implikatur: 'Wer im Holocaust gelitten hat, sollte sich nun anständig und friedlich benehmen'). Schließlich wird auch implizit über die als Fakt ausgegebene Aussage „dass Israelis alles dürfen“ die Existenz und Ausnutzung eines jüdischen Sonderstatus, also ebenfalls ein tradiertes judeophobes Stereotyp, kommuniziert. ${ }^{20}$

Beispiel (7) stellt die Aberkennung des Existenzrechts eines Nationalstaates Israel allein politisch begründet dar, ohne dass weitere Indikatoren für Antisemitismus vorhanden sind. Eine antizionistische Einstellung kommt bei diesem promovierten Verfasser zum Ausdruck. Der Antizionismus (der aus historischer Perspektive als eine von Skepsis und Abwehr gekennzeichnete Haltung gegenüber der jüdischen Nationalbewegung zu betrachten ist) zeichnet sich dadurch aus, dass die Idee eines jüdischen Nationalstaates strikt abgelehnt wird.

„Sehr geehrter Herr Botschafter Stein. Die beste Lösung für einen Dauerhaften Frieden im Nahen Osten ist die Auflösung des Staates Israel [...].“ [IBD_23.03.2007_Hof_001]

20 Als kontextuelle Information ist bei diesem Beispiel auch zu berücksichtigen, dass es sich bei dem Verfasser um einen extrem antisemitisch eingestellten Dauerschreiber (sowohl an die IBD als auch an den ZJD) handelt. 
In diesem Zusammenhang muss man sich vor Augen führen, dass Antizionismus, der besonders von Linken und Linksextremisten vertreten wird, heute nur noch als Leugnung des Rechts von Juden auf den bereits bestehenden Nationalstaat existiert (s. Kloke ${ }^{2}$ 1994: 19). Diese Einstellung geht also weit über die bloß theoretische Ablehnung der politischen Idee des Zionismus hinaus, da diese antizionistische Haltung als praktische Konsequenz die Abschaffung des jüdischen Staates fordert. Damit erweist sich der aktuelle Antizionismus als eine Ausdrucksform der durch Intoleranz und Feindseligkeit geprägten anti-jüdischen Konzeptualisierung, die genuin jüdische Existenz als solche nicht akzeptiert und den Juden kollektiv ihre Berechtigung als Juden aberkennt. Die Forderung, Israel als jüdischen Staat aufzulösen, reiht sich somit auch in das Spektrum der diversen „Lösungsvorschläge für das Judenproblem“ ein, die im Laufe der Jahrhunderte vorgebracht worden sind (s. hierzu Kap.10.3).

„Der aktuelle Antizionismus, der die Existenz des jüdischen Staates ablehnt oder delegitimiert, funktioniert weitgehend 'als Ticket für die tradierte Judenfeindschaft, seine ultima ratio ist die Vernichtung Israels’ (Weiß 2005).“ (Rensmann/Schoeps 2008: 17)

Israel-Kritik stellt, wie oben beschrieben, eine kommunikative Handlung dar, die ein auf rationalen Prinzipien und sozial akzeptierten Werten basierendes Argumentationsmuster aufweist. Dieses richtet sich nach Wahrhaftigkeit und Zielorientiertheit sowie der Einhaltung sprachlicher Angemessenheitskonventionen. Demgegenüber stellt Anti-Israelismus ein auf irrealen judeophoben Feindbildkonstrukten sowie irrationalen Wunsch- und Zielvorstellungen fußendes Aggressionsverhalten ${ }^{21}$ dar. Dieses Aggressionsverhalten spiegelt sich in den Äußerungen wider, die als verbale Gewalt zu charakterisieren sind, und zeigt insgesamt die globale Respektverweigerung und Existenzaberkennung, die explizit wie in (8) oder implizit wie in (9) ausgedrückt wird:

$$
\begin{aligned}
& \text { „Sind Juden eigentlich Menschen? Diese Frage kann man angesichts der } \\
& \text { Verbrechen in Gaza, Lebanon nur mit einem klaren Nein beantworten. } \\
& \text { Vielleicht sollten wir mal die juedischen Buecher bei euch wieder anwen- } \\
& \text { den! Denn man weiss ja was dort geschrieben wird - rassistischer Mist } \\
& \text { und dabei seid ihr selber die dreckigsten Rassisten. Abmarsch in die Gas- } \\
& \text { kammer! Heil Zion!“ [ZJD_Gaza2009_677/816_Pan_001] }
\end{aligned}
$$

21 Anti-Israelismus kann einerseits als mentale Einstellung, andererseits als wahrnehmbares Verhalten, das auf der israelfeindlichen Einstellung basiert, verstanden werden. Wir sehen beide Phänomene in untrennbarer Wechselwirkung. Da wir im Folgenden Formen des verbal manifesten Anti-Israelismus betrachten, betonen wir hier die handlungsorientierte und wahrnehmbare Dimension dieses komplexen Phänomens. 


$$
\begin{aligned}
& \text { „Israel ist ein historischer Fehler. Es muss eine Lösung gefunden } \\
& \text { werden.“[ZJD_2009_Gaza787/816_Her_001] }
\end{aligned}
$$

Bei allen Variationen liegt den verbalen Aggressionen gegenüber Israel konzeptuell eine feindselige, von starken Abwehrgefühlen und mentalen Stereotypen geprägte Einstellung zugrunde, die eine extreme Voreingenommenheit ${ }^{22}$ darstellt. Die Klassifikation und Bewertung von Personen, Sachverhalten und Prozessen ist dadurch bereits mental im Kopf der Menschen vollzogen, ganz gleich, was sich tatsächlich in der realen Welt abspielt. Diese Voreingenommenheit verhindert eine realistische Einschätzung außersprachlicher Ereignisse und führt zu pauschalen Vor-Urteilen sowie einseitigen Schuldzuweisungen. Anti-Israelismus hat wie jeder andere „Ismus“ kein empirisches Fundament, entspricht also nicht den realen Strukturen in der Welt, sondern stellt ein Deutungsschema in den Köpfen von Menschen dar. Israel wird als schlecht, böse, verkommen angesehen, seine Existenz entsprechend als Provokation und Ärgernis oder als Bedrohung empfunden.

(10) „Wir sind empört über die agressive Politik Israels. Dieser Staat ist eine große Gefahr für den Weltfrieden.“ [IBD_22.03.2004_Sch_001]

(11) „Haut ab! Verschwindet endlich von der Erde, ihr Mördergesindel!!“ [IBD_04.07.2006_Postkarte]

(12) „ihr juden seid ein schandfleck auf der weltkarte.“

[IBD_16.07.2006_Man_001]

Das „Anti“ im Anti-Israelismus gibt an, dass es sich um eine pauschale Negativbewertung handelt. Der „Ismus“ indiziert, dass kollektiv und übergeneralisierend alles, was als israelisch kategorisiert wird, per definitionem durch das „Anti“ determiniert wird. Der Komplexität und Heterogenität der Außenwelt wird ein starres, konzeptuell geschlossenes Orientierungs- und Kategorisierungsmuster entgegengestellt, das keinen Raum für alternative Sichtweisen lässt. Die eigene Perspektive wird verabsolutiert, so dass ein kognitives bzw. kommunikatives Miteinander bzw. ein Meinungsaustausch (mit dem ohnehin als nicht ebenbürtigen, da „moralisch verkommenen“, vor-verurteilten Gegenüber) kategorisch ausgeschlossen wird. Während legitime und ernst gemeinte Kritik Verbesserungsopti-

22 Zum Phänomen der Voreingenommenheit (Bias) s. u. a. Assmann (2009) und Stangor (2009). 
onen $^{23}$ anbietet, ohne den Kritisierten auszuschließen, zielt der Anti-Israelismus nur auf die Stigmatisierung und letztlich auf die radikale Veränderung oder Auflösung des jüdischen Staates.

\subsection{Kennzeichen des antisemitischen Anti-Israelismus}

\subsubsection{De-Realisierung: Falschaussagen, Ausblendungen, Verzerrungen, Monoperspektivierungen}

Aufgrund der mentalen und emotionalen Voreingenommenheit gegenüber Israel sind Wahrnehmungs-, Bewusstseins- und Klassifikationsprozesse bei betroffenen Personen stark eingeschränkt bzw. auf eine einzige Deutung hin ausgerichtet. In diesem Sinne unterliegen Menschen mit einer anti-israelischen Einstellung einer Realitätsstörung, ${ }^{24}$ die sich kommunikativ in Sprachmustern zeigt, die Sprachezu-Welt-Strukturen in ein Missverhältnis bringen. Die Referenzialisierungen, also die sprachlichen Darstellungen von außersprachlichen Sachverhalten, die diese Menschen produzieren, weisen spezifische Merkmale der Inkongruenz (wie kollektive Schuldzuweisungen, pauschale Negativattribuierungen, hyperbolische Übertreibungen, Monoperspektivierungen und unverhältnismäßige Analogien) auf. Diese lassen sich semantisch-konzeptuell in die oben genannten Phänomene

23 Eine Sprechhandlung, die keine Optionen auf der Adressatenseite zulässt, ist keine Kritik, sondern ein Befehl, der etwas autoritär und machtbewusst erzwingen will, und bevormundet aus einer asymmetrischen Situation heraus den Kommunikationspartner. Liegt keine Befehlsposition vor, handelt es sich um die Artikulation von Intoleranz. Eine Sprechhandlung, die das kommunikative Gegenüber angreift und abwertet, ohne Alternativen aufzuzeigen, ist eine Beleidigung und eine Bedrohung.

24 Derealisation bzw. Depersonalisation werden in der Psychopathologie als Syndrome betrachtet, die dazu führen, dass Menschen die eigene Person und/oder die Umwelt als fremd und unnormal empfinden (vgl. u. a. Wolfradt 2003). Wir sprechen dagegen von DeRealisierung als einem Phänomen, das sich ergibt, wenn ein mentales Deutungsschema zu einem spezifischen außersprachlichen Sachverhalt, beim Anti-Israelismus zu einem Land, dazu führt, dass dieser Sachverhalt verzerrt, eingeengt oder komplett falsch wahrgenommen und bewertet wird. Das Kriterium der Falschheit oder Verzerrung ergibt sich aus der Inkongruenz zwischen subjektiver Betrachterperspektive und objektiver bzw. intersubjektiver Sachlage. Auf das Problem der Überprüfbarkeit von (absoluter) Wahrheit an sich haben wir bereits hingewiesen, vgl. Kap. 3. Gemeinsam haben Derealisation und De-Realisierung, dass es sich um Realitäts(wahrnehmungs)störungen handelt. Mitscherlich/Mitscherlich (1967: 76) haben das Phänomen angesichts der Vermeidung von Trauerarbeit nach dem Holocaust erörtert. Vgl. auch Hegener (2006: $18 \mathrm{f}$.), für den Antisemitismus eine Denkstörung sowie eine Störung des Wirklichkeitssinnes ist. 
der Dämonisierung, Delegitimierung und Doppelstandardisierung einordnen. Die drei Ds ergeben sich somit als unmittelbare Folge der de-realisierten Einstellung und bauen zu einem großen Teil aufeinander auf bzw. stützen sich gegenseitig in der pseudo-rationalen „Argumentation“.

Wie wir in Kap. 3 ausgeführt haben, bildet Sprache nicht nur Realität ab, sie erzeugt auch über semantische Strukturen Realitäten, die mit der tatsächlichen Welt nichts zu tun haben (müssen). Verbale De-Realisierung betrifft das Verhältnis von Sprache und Welt. De-realisierende sprachliche Äußerungen bilden die Realität nicht so ab, wie sie tatsächlich (und intersubjektiv erfahrbar) ist, sondern konstituieren aufgrund ihres semantischen Gehalts eigene, subjektive Realitäten. Die Abbildungs- bzw. Darstellungsfunktion von Sprache, die maßgeblich auf dem Kriterium der Wahrheit(swertüberprüfung) beruht, wird hierbei von den Sprachproduzenten instrumentalisiert, um die Sachverhalte der Welt gemäß ihrer Einstellung zu verbalisieren. So wird über de-realisierende Sprachstrukturen ein Zerrbild von Israel gezeichnet:

„Es ist eine Schande, was sich Ihr Land leistet! Es gibt keine Verhältnismäßigkeit. 1 Israelauge gegen 500 andere. Ein Krieg und Völkermord gegen ein paar entführte Israelis. Clusterbomben in Wohngebiete. Ein Kriegsverbrechen jagt das nächste. Sagen Sie mir nicht ich bin ein Neonazi. Ich bin Humanist. Die eigentlichen Faschisten (Nazis) regieren in Israel.“[IBD_31.07.2006_Pop_001]

(14) „Israel ist ein blutrünstiger, brutaler und agressiver Apartheids-Staat“ [IBD_06.05.2009_Kre_001]

Da die De-Realisierungen aber als repräsentative Sprechakte ${ }^{25}$ formuliert werden, bleibt der Anspruch auf Wahrhaftigkeit dabei erhalten und dies spiegelt die Geschlossenheit des Glaubenssystems der Sprachbenutzer wider (s. hierzu die Strategien der Rechtfertigung und Legitimierung in Kap.11).

Es werden in den Tausenden von E-Mails und Briefen an den ZJD und die IBD, aber auch öffentlich in allen Bereichen des Internets (s. hierzu Schwarz-Friesel 2012a) so viele de-realisierende Behauptungen über Israel artikuliert (die alle den jüdischen Staat und seine Bürger in der Aggressorrolle darstellen und teilweise

25 Repräsentative (assertive) Sprechakte zeichnen sich dadurch aus, dass der Sprecher sich auf die Wahrheit seiner Aussage über die Welt verpflichtet. Die Sprache richtet sich also nach der Welt. Zugleich gilt die Voraussetzung, dass der Sprecher davon überzeugt ist, was er sagt und dass hinreichend Gründe vorhanden sind, die diese Überzeugung stützen. Somit haben diese Äußerungen unter Umständen auch eine große Wirkungsmacht auf andere. 
an groteske Verschwörungstheorien gekoppelt sind), dass wir uns hier auf einige repräsentative und besonders frequente Typen konzentrieren.

Da einige Leser dieses Buches unter Umständen bereits an eine Reihe von derealisierenden Sprachgebrauchsmustern in Bezug auf Israel aus dem öffentlichen Kommunikationsraum gewöhnt sind, möchten wir an dieser Stelle ein Leseexperiment einfügen, um eventuelle Habitualisierungseffekte $\mathrm{zu}$ durchbrechen und mittels einer Analogie die Dimension der De-Realisierung besonders deutlich zu veranschaulichen:
„Mit Abscheu und Entsetzen haben wir aus der Presse erfahren, dass die bundesdeutsche GSG9 wieder einmal in SS-Manier mit unverhält- nismäßiger Gewalt gegen anständige junge Menschen aufrechter Gesin- nung vorgegangen ist, die lediglich einen verzweifelten Freiheitskampf gegen den Staatsterror Deutschlands führen. Angeblich handelte es sich um einen 'Anti-Terror-Einsatz'. Die Bundesrepublik Deutschland ist ein faschistisches Verbrecherregime, das wie gehabt im Geiste der primiti- ven Germanen Andersdenkende brutalisiert und mutwillig zerstört und sich genau wie unter Hitler mit großer Aggressivität gegenüber seinen europäischen Nachbarn verhält. Seine rassistische und unglaublich ego- istische Finanzpolitik ist eine Schande für die gesamte zivilisierte Welt, entspricht aber genau der Gesinnung dieses grausamen Tätervolkes. Was Deutsche zur Zeit mit den armen, unglücklichen Griechen machen, ist empörend und bedroht den Weltfrieden! Deutschland sollte schnellst- möglich aufgelöst und unter UN-Aufsicht gestellt werden. Wir werden jedenfalls alle aus Deutschland kommenden Produkte von nun an kon- sequent boykottieren. PS: Wir sind wirklich keine Deutschenhasser, aber unser Gewissen lässt uns angesichts der Verbrechen dieses Unrechts- staates nicht mehr schweigen.“

Dieser (von uns eigens zum Zweck der Illustration konstruierte) Text ${ }^{26}$ zeigt eine Referenzialisierung Deutschlands, die sofort als falsch, verzerrt, überzogen und irreal erkannt wird. Dass Israel seit Jahren Opfer exakt solcher de-realisierenden Darstellungen und Anschuldigungen ist, wird jedoch nicht so bewusst reflektiert und erkannt. ${ }^{27}$ Die mittlerweile frequent benutzten Brachialverbalismen haben

26 Einige der genannten Argumente finden sich allerdings tatsächlich, polemisch zugespitzt, in der aktuellen Diskussion um die Rolle der deutschen EU- und Finanzpolitik.

27 In den letzten vier Jahren wurden in verschiedenen Universitätsseminaren in Jena und Berlin de-realisierte Texte wie (15) zu Deutschland, Frankreich, Australien und Israel in Leseexperimenten vorgelegt: Während über 95 Prozent der Probanden sofort und ohne 
ihre Spuren hinterlassen: Das über die Sprache konstruierte Zerr- und Feindbild Israels wird bereits weithin akzeptiert.

Typisch für die de-realisierte Sichtweise in Bezug auf Israel ist insgesamt, dass es als alleiniger Aggressor im Nahostkonflikt dargestellt wird:

\begin{abstract}
„Mir ist völlig klar, dass durch eine solche Gewaltpolitik Israels der Hass in den Arabischen Staaten immer mehr zunehmen wird und Israel niemals mehr zur Ruhe kommen wird. Aber das hat Israel - und nur Israel - zu vertreten und zu verantworten. So, das lag mir schon lange im Magen und mußte einmal gesagt werden!“ [ZJD_08.08.2006_Kre_001]
\end{abstract}

Um das einseitige Aggressorbild Israels aufrechterhalten $\mathrm{zu}$ können, werden Referenzialisierungen konstruiert, die auf Falschaussagen basieren. Die Verfälschung von Fakten erfolgt durch Umkehrung, Auslassung oder Relativierung von Sachverhaltsinformationen. Auf diese Weise erzeugen die sprachlichen Strukturen ein Feindbild ISRAEL, das zwar mit der Realität nicht kompatibel ist, dafür aber exakt das repräsentiert, was dem judeophoben Weltbild entspricht und das damit genau die ihm zugewiesene Funktion erfüllt (s. hierzu Kap. 9).

Eine (geschichtsverfälschende) Umkehrung findet z. B. statt, wenn behauptet wird, Israel habe von Anfang an aktiv Kriege gegen die arabischen Nachbarstaaten initiiert und trage die alleinige Schuld für die instabile Lage in Nahost (wobei die aggressive Rolle kollektiv auf die ,jüdische Mentalität“ zurückgeführt wird):

„Selbst Ihnen müßte doch bekannt sein,daß Israel ein sehr aggresiver Staat ist. Sie wissen doch wie viele Kriege der Judenstaat begonnen hat.“ [ZJD_Gaza2009_61/816_Sch_001]

\begin{abstract}
„Euer Staat war von Anfang an eine Missgeburt und durch Betrug an den Arabern von bestimmten Mächten durchgedrückt worden. Ihr solltet euch als Gast in Region fühlen und eine normale Beziehung zu euren Nachbarn pflegen. Offensichtlich lässt das eure Mentalität nicht zu.“ [IBD_16.07.2006_ano_011]
\end{abstract}

Die Auslassung von Informationen stabilisiert dagegen vor allem die Argumentation, das israelische Verhalten gegenüber den „wehrlosen und friedlichen Palästi-

zu zögern die Texte zu den drei erstgenannten Ländern als „falsch“, „grotesk“, „irre“ oder „verrückt“ charakterisierten, sahen über 60 Prozent nichts Auffälliges an den anti-israelischen Texten (s. Schwarz-Friesel 2011b). 
nensern“(an die IBD 2006) sei rein willkürlich (womit die Lesart 'Israelis sind von Natur aus mutwillig böse und verkommen’ gestützt wird):

„Ihr drangsaliert die armen P. völlig grundlos und sperrt sie hinter Mauern. Pfui!““[IBD_10.03.2011_Lar_001]

Dass es sich um Sicherheitsmaßnahmen zum Schutz der israelischen Zivilbevölkerung handelt (die nach zahlreichen terroristischen Attacken eingeführt wurden), bleibt unerwähnt. Ausgeblendet wird auch stets, dass Raketenangriffe des israelischen Militärs auf Ziele der Hamas Antworten bzw. Gegenschläge auf zuvor erfolgte Raketenbeschüsse israelischer Gebiete sind (vgl. auch Bsp. (37)). „Grundlos“, „vorsätzlich“ und „völlig unverhältnismäßig“ sind diesen Verfassern zufolge prinzipiell alle Tötungsaktionen des israelischen Militärs, auch dann, wenn sie klar erkennbar in Notwehrsituationen vollzogen wurden.

Wenn Aggressionen von palästinensischer Seite Erwähnung finden, werden sie entweder realitätsverzerrend relativiert und/oder gerechtfertigt: Aus Terroristen werden „Kinder und Jugendliche“, aus Raketen „Gummigeschosse“, „Steine“ oder „Platzpatronen“, aus Bombenattentaten „verzweifelte Notwehraktionen“ oder „legitime Freiheitskämpfe“:

„Die Armee des Mörder-, Folter- und Landraubstaates Israel hat wieder einen gloriosen Sieg über Steine werfende palästinensische Kinder und Jugendliche errungen.“ [IBD_28.03.2004_Wul_001; per Brief]

\begin{abstract}
„Was ihr Juden heute im Gazastreifen gemacht habt, ist brutaler Mord, sonst nichts. Man hat ein paar Platzpatronen hinübergeschossen, und ihr kommt mit Kampfjets und Helis, mordet und verschwindet. Ihr seid Bestien. Ich werde alles tun, um meine Mitmenschen gegen Israel aufzuhetzen.“[ZJD_27.12.2008_ano_001]
\end{abstract}

Demgegenüber sind militärische Aktionen Israels angeblich „Massaker gegen Wehrlose“, „Krieg gegen Zivilisten“, „Bluttaten“, „mörderisches Blutvergießen“, „ethnische Säuberung“ und „Staatsterrorismus“, es sind „gnadenlose Schandtaten“, „unverantwortliche Unmenschlichkeiten“ und „nicht hinnehmbare Brutalitäten“. Die lexikalischen Vertauschungen stützen somit immer die anti-israelische Gesamtbewertung.

Ein semantisches Prinzip zieht sich bei der verbalen De-Realisierung Israels kontinuierlich (und unabhängig von politischer Ausrichtung oder Bildungsunterschieden) durch die Darstellungen: Minimierung von Gewalt und Gefahrenpo- 
tenzial bei der nicht-israelischen Konfliktpartei bei gleichzeitiger Maximierung von Aggressivität und Schuld auf israelischer Seite.

(22) „Ich habe vollstes Verständniss das sich Hamas - Hisbollah - Dschihad - Fatah gegen den nicht enden wollenden Terror Israels wehrt. Sie sind die Terroristen ,sie stehlen und besetzen Land Sie diskreminieren täglich Araber. nicht umgedreht.Warum fragen sie sich nicht mal selbst ,warum Israel seit 4000 Jahren ständig in Konflikten,in Kriegen Verfolgung Vertreibung verstrickt ist.“[IBD_20.07.2006_Die_001]

(23) „Hallo aus München, es wäre an der Zeit, daß Israel die Atombomben abbaut, die Israel auf den Iran und andere friedliche Nationen gerichtet hat, bevor Israel Forderungen an z.B. den Iran stellt und ihnen verbieten will, friedliche Atomenergie zu erzeugen.--““[IBD_30.10.2007_ano_001]

Die unterstellte und als genuin israelisch definierte Aggressivität wird dabei oft (mittels seit Jahrhunderten kollektiv allen Juden zugeschriebenen Eigenschaften) pseudo-kausal und rassistisch begründet, womit das Stereotyp des EWIGEN JUDEN aktiviert wird:

(24) „Ihr Juden koennt es nicht lassen. Kuemmert Euch um Eure eigenen Schandtaten. ...Euer Staat ist eine Missgeburt wie Ihr selber wisst. Schaut das ihr mit euren Nachbarn zurecht kommt. Aber ihr fühlt Euch ja als das auserlesene Volk.“[IBD_12.06.2006_ano_001]

(25) „Juden! Phosphorbomben gegen Zivilisten einsetzen. MÖRDER! Gibt es denn ein noch fieseres VOlk als Euch?“ [IBD_27.10.2006_ano_001]

Eine implizit rassistische Argumentation ist bei selbsternannten Humanisten und Friedensaktivisten zu verzeichnen, wenn sie Israelis über ihr Jüdisch-Sein identifizieren und unterstellen, individuelle Leiderfahrungen von Juden im Holocaust müssten als kollektive Erfahrungswerte auf Israelis übertragen werden und sie besonders sensibel für Gewalt und Unrecht gemacht haben. Dass sie es nicht sind, so die (zumeist gebildeten) Schreiber, mache sie noch verabscheuungswürdiger.

(26) „[...] dass der Holocaust oft nur Mittel zum Zweck war - bis heute. Wie sonst wäre es möglich, dass gerade Juden anderen unschuldigen Menschen so viel Leid zufügen können“ [ZJD_30.07.2006_Ans_001] 
Aufgrund der besonderen Leiderfahrung des jüdischen Volkes werden Erwartungen an den Staat Israel gestellt, die an kein anderes Land der Welt herangetragen werden (s. hierzu den Aspekt des doppelten Standards):

„Unfassbar, diese Grausamkeit -und das mit Ihrer Geschichte!“ [IBD_25.4.2010_Erl_001]

Israel und seine gesamte jüdische Bevölkerung werden einseitig auf militärische Gewalt reduziert. Zudem wird eine homogene Konzeptualisierung etabliert, da nicht zwischen Regierung und Volk unterschieden wird.

„hiermit fordere ich Sie auf, sich öffentlich für die folgenden nachweislichen Verbrechen, die von Ihren meiner Meinung nach bis heute feigen und blutrünstigen israelischen Soldaten und der meiner Meinung nach bis heute feigen und blutrünstigen israelischen Bevölkerung an der palästinensischen Bevölkerung in der Zeit von 1967 bis aktuell verübt worden sind zu entschuldigen: [...]“ [IBD_07.01.2011_Urb_001]

Auch bei gebildeten Schreibern ist die de-realisierte Wahrnehmung Israels durch eine starke Monoperspektive auf den Nahostkonflikt gekennzeichnet, Israel wird vorgeworfen, mit Staatsterror gegen die Palästinenser vorzugehen und somit weder demokratischen noch sozial-ethischen Ansprüchen gerecht zu werden.

(29) „Wer auch nur über ein bisschen Bildung verfügt, weiß, dass die gegenwärtigen Gewaltakte an der palestinensischen Bevölkerung KEINE Akte der Selbstverteidigung sind. Was Israel da gerade anstellt, sind Verbrechen gegen die Menschlichkeit. Es zielt auf Vernichtung, Auslöschung und Ausrottung. Israel betreibt den Holocaust an den Bewohnern Palestinas. Es wird offenbar, daß Israel eben nicht zum Kreis der aufgeklärt humanistischen Völker zählt, sondern kulturtell und geistig-moralisch im barbarischen Zustand verblieben ist.“ [ZJD_Gaza2009_552_Mer_001]

(30) „Ich verachte jeden in eurer Gemeinde, der den Israelischen Terror in Palästina unterstützt. Das was Ihr (und ich meine damit das demokratisch wählende israelische Volk) veranstaltet, ist mindestens genau so verwerflich wie der Holocaust. Ich verachte jeden, der unter diesen Umständen auch nur noch ein einziges Denkmal für die Opfer des Holocausts verlangt.“[ZJD_01.09.2006_Sal_001] 
Dabei kommt es immer wieder zu Verschmelzungen und Gleichsetzungen von jüdischen und israelischen Belangen, wie in (30) oder (31):

„solange Sie nicht begreifen, dass Ihr Terror [...] keine Verständigung herbeiführen kann, solange werden Sie zu Recht von humanistisch geprägten Menschen verachtet.“[ZJD_Gaza2009_27/816_Stü_001]

Nach dem Pars-pro-toto-Prinzip wird der gesamte Staat Israel über die Wahrnehmung der militärischen Aktivitäten ${ }^{28}$ identifiziert. Von den „differentia specifica“ werden lediglich die negativen Merkmale fokussiert und benutzt, um den jüdischen Staat und seine Bevölkerung zu definieren. Von dieser begrenzten Perspektive und der spezifisch eingeengten Konzeptkategorie ISRAEL wird dann ein mentaler Transfer vollzogen, der nun eine konzeptuelle Elaboration beinhaltet: Israel, der „aggressive Unrechtsstaat“ symbolisiert Jüdisch-Sein. Die Konzeptualisierung des KOLLEKTIVEN JUDEN ISRAEL wird zur Identifikations- und Bewertungsbasis aller Juden. Entsprechend werden die anklagenden und schuldzuweisenden Schreiben an den Zentralrat in Deutschland gerichtet.

\section{Dekontextualisierung und die Apartheidanalogie}

Dass allein die Verwendung eines einzelnen Lexems eine spezifische, de-realisierende Konzeptualisierung konstituieren kann, zeigt das Kompositum Apartheidstaat.

„Hier ist die Rede von einem brutalen, rassistischen Apartheits-Staat.“ [ZJD_27.10.2006_Kna_001]

Oftmals wird Israel als Apartheidstaat, Apartheidregime (oder semantisch überspezifiziert gar als rassistischer Apartheidstaat) bezeichnet, und zwar auch von vielen Akademikern und Politikern, die aufgrund ihres Bildungsgrads eigentlich wissen sollten, was das Wort bedeutet.

28 Dass die Mehrheit der Israelis allen Umfragen in Israel zufolge Frieden mit den Palästinensern möchte und dabei zu diversen Kompromissen sowie Zugeständnissen bereit ist, wird nur selten und in der Regel lediglich in den E-Mails erwähnt, die legitime Kritik üben. In den anti-israelischen Zuschriften wird die Bevölkerung Israels über die Nennung fanatisierter Siedler und/oder Nationalreligiöser, rechtsgerichteter Politiker sowie militärischer Einsatzkräfte definiert. 
Unter Apartheid versteht man die staatlich gelenkte, institutionalisierte Rassentrennung, so wie sie im ehemaligen Südafrika praktiziert wurde, wobei bestimmte Ethnien innerhalb der Bevölkerung gesetzlich und sozial benachteiligt wurden. Wäre Israel de facto ein solcher Staat, so wäre scharfe internationale Kritik nicht nur angemessen, sondern notwendig. Doch Israel ist so wenig Apartheidstaat wie die Bundesrepublik Deutschland. Die nicht-jüdischen Bürger, gleich ob es arabische Christen, Drusen oder Muslime sind, haben exakt die gleichen Rechte, Bildungs-, Entwicklungs- und Aufstiegschancen wie die jüdischen Staatsbürger. ${ }^{29}$ Entsprechend sind arabische Israelis in allen Bereichen der Gesellschaft vertreten, als Geschäftsleute, Ärzte, Polizisten, Soldaten, Rechtsanwälte, Abgeordnete. Dennoch wird Israel durch die Referenzialisierung als Apartheidstaat in direkte Analogie zu dem ehemaligen Unrechtsregime Südafrikas $^{30}$ gesetzt. Das Wort Apartheid wird aus seinem historischen Zusammenhang gerissen und dekontextualisiert. Dekontextualisierung bedeutet im Sprachgebrauch die Herauslösung eines Wortes oder Satzes aus seinem ursprünglichen Bedeutungszusammenhang und seine Übertragung (Rekontextualisierung) in einen anderen Kontext. Die Originalbedeutung unterliegt dabei einer semantischen Verengung oder Erweiterung bzw. einer grundlegenden Veränderung (z. B. durch Merkmalstransferprozesse). Apartheid wird in Bezug auf Israel im doppelten Sinne als Stigma-Wort benutzt: Zum einen dient es der Verleumdung des demokratischen Staatswesens, zum anderen gibt es eine pejorativ verzerrende Darstellung der Sicherheitspolitik Israels. Mit Apartheid meinen viele auch die aus Sicherheitsgründen (nach exzessiven terroristischen Attentaten innerhalb der Staatsgrenzen Israels) vollzogene Abgrenzung und Kontrollpolitik in Bezug auf die Palästinenser (die nicht Bürger Israels sind). Diese Politik, die in jedem anderen Land der Welt als legitime Selbstverteidigungs- und Anti-Terror-Maßnahmen ${ }^{31}$ zum Schutz der eigenen Bevölkerung betrachtet und akzeptiert würde, wird im Falle Israels als „Staatsterror“, „Rassismus“ und „Willkür“ interpretiert.

29 Dies ist kein Buch über Israel oder über den Nahostkonflikt, aber um die Diskrepanz zwischen der realen Welt und den de-realisierenden Äußerungen klarmachen zu können, um das manipulative und antisemitische Potenzial anti-israelischer Äußerungen transparent zu machen, müssen wir teilweise kurz auf außersprachliche Sachverhalte eingehen.

30 Diese diffamierende Analogie findet sich nicht nur im deutschen Diskurs, s. Wistrich (2010: $35 \mathrm{f}$.): „The big lie that Israel is an apartheid state has become firmly entrenched in recent years in many Western countries."

31 Gedankenspiele und mentale Analogien können veranschaulichen, wie unverhältnismäßig hier geurteilt wird (s. Doppelstandard): Man stelle sich vor, was die deutsche Regierung tun würde, um ihre Bürger zu schützen, wenn aus den benachbarten Grenzregionen Terroristen Raketen auf deutsche Städte feuern würden oder Selbstmordattentäter nach Deutschland kommen würden, um Schulbusse in die Luft zu sprengen, und wie die deutschen Bürger auf 

„Sie haben aus Palestinä durch brutale Machtausübung ein Gefängnis gemach, weil sie das Recht des Stärkeren unbarmherzig anwenden!“ [IBD_02.05.2008_Zu_001]

Aus der Tatsache, dass alle Palästinenser, auch die nicht-radikalen und friedenswilligen, unter den Sicherheitsmauern und den zum Teil drastischen Grenzkontrollen $^{32} \mathrm{zu}$ leiden haben, entstand über die Dekontextualisierung eine konzeptuelle Ausweitung und referenzielle Übergeneralisierung (von der Praxis der Grenzpolitik wurden Merkmale auf den Staat Israel an sich übertragen), nämlich das Stereotyp UNTERDRÜCKER- UND UNRECHTSSTAAT. Dieses Konzept wiederum wurde - aus dem ursprünglichen Kontext gerissen - spezifiziert, und nun wird Unrechtsstaat als gegen Israel gerichtetes Diffamierungswort benutzt. Die Macht von Wörtern liegt $\mathrm{u}$. a. darin, dass ihre Bedeutungen spezifische mentale Bilder von hoher emotionaler Wirkung aktivieren. Das Wort Apartheid lässt im Bewusstsein (in Analogie zum ehemaligen Südafrika) ein Szenario entstehen, in dem bestimmte Menschen als Bürger eines Staates benachteiligt und ausgegrenzt werden. Aus dieser Konzeptualisierung leiten viele eine inhumane ,jüdische Ethik“ ab. Dadurch wird implizit das tradierte Stereotyp von Juden als eingeschworener Gemeinschaft, die nur aus Eigeninteresse handelt und kein Mitleid für andere Menschen fühlt, aktiviert. Judentum wird somit allgemein mit israelischer Nahostpolitik gleichgesetzt.

„Leider ist es aber so, dass ein Jüdisches Leben von Ihnen weit über ein arabisches gestellt wird.“[ZJD_31.07.2006_Omi_001]

Da diese Form der Diskriminierung verpönt ist und von zivilisierten und demokratischen Staaten als überholt und inhuman abgelehnt wird, stigmatisiert die Attribuierung Apartheid Israel als rückständigen, außerhalb der modernen Weltgemeinschaft stehenden Unrechtsstaat. Entsprechend werden in Konstruktionen, in denen dieses Wort benutzt wird, auch viele semantisch äquivalente Lexeme wie primitiv, inhuman, unzivilisiert, rassistisch, brutal, blutrünstig, mörderisch und besonders oft alttestamentarisch verwendet, um diese (judeophobe) Konzeptualisierung $\mathrm{zu}$ intensivieren.

solche Attacken reagieren würden.

32 Dabei werden vorkommende Fälle von Schikanen zum Anlass genommen, ganz Israel anzuklagen wie in der folgenden E-Mail: „Was tun Israels Soldaten an den Checkpoints? Sie demütigen die Menschen aus den Palästinensergebieten! ISRAEL, SCHÄME DICH!!!“ [IBD_29.09.2008_Eng_001]. Dass gesetzeswidrige Brutalitäten einzelner Soldaten von der israelischen Militärführung geahndet werden, wird dabei ausgeblendet. 
„Es geht mittlerweile über alles hinaus, was man von zivilisierten Menschen erwarten kann. Das ist nicht mehr Notwehr, das ist blutrünstige, alttestamentarische Rache [...].“[ZJD_18.04.2002_Eck_001]

Besonders häufig findet sich in diesem Zusammenhang die moralische Gesamtverurteilung, Israel sei eine Schande für die zivilisierte Gemeinschaft und solle sich schämen. ${ }^{33}$

$$
\text { „Israel ist eine Schande für die ganze Welt!“ [IBD_01.09.2006_ano_001] }
$$

„Sie müssen sich schämen, einem Terroristenstaat anzugehören, der seine Gegner und Unschuldige mit Raktenangriffen liquidiert.“ [IBD_22.03.2004_Kis_001]

Das Apartheidargument, das als Diffamierungsmittel von Juden- und Israelhassern erfunden und kommuniziert wurde, wird mittlerweile weithin artikuliert, auch in der Mitte der Gesellschaft, und kann dort sein persuasives Potenzial entfalten..$^{34}$ „Apartheidstaat Israel“, ein de-realisierendes und stigmatisierendes Phantasiekonstrukt, ist zu einem Schlagwort geworden, dessen Wahrheitswert nicht mehr hinterfragt oder geprüft wird. NS-Vergleiche stellen in Bezug auf Israel und/oder Juden eine weitere Form der extremen Dekontextualisierung dar. Wir werden diese Form der de-realisierenden Diffamierung im folgenden Kapitel als spezifische Variante der Dämonisierung beschreiben.

Ähnlich oft wie als Apartheidstaat wird Israel als ein Terrorstaat dargestellt, der angeblich seit seiner Gründung mit großer Brutalität die arabischen Nachbar-

33 Das emotionsdarstellende Lexem schämen wird (frequent gekoppelt an das Wort Schande) signifikant oft benutzt, um Israel gegenüber mit moralischer Überlegenheit entgegenzutreten. Hier wird ganz offensichtlich mittels der Täter-Opfer-Umkehr die emotionale Dimension von Scham und Schande, die kollektiv in Bezug auf die deutsche NS-Vergangenheit gefühlt werden sollte bzw. müsste, auf Israel übertragen (s. hierzu Kap. 9.3.2).

34 In jüngster Zeit lassen sich auch Formen des populistischen Anti-Israelismus beobachten. Dass ein aktiver Spitzenpolitiker nicht-extremer Ausrichtung de-realisierende, den Staat Israel diffamierende Formulierungen benutzt, ist bislang nicht oft zu konstatieren. Das Beispiel, das Sigmar Gabriel bot, zeigt aber, wie schnell israelfeindliche Sprachfloskeln, die habituell im rechtsextremistischen und fundamentalistischen Diskurs artikuliert werden, Eingang in die alltägliche Sprachgebrauchspraxis finden. Gabriel hatte am Mittwoch, den 14.03.12 um 14.31 Uhr auf seine Facebook-Seite den folgenden Text gestellt: „Ich war gerade in Hebron. Das ist für Palästinenser ein rechtsfreier Raum. Das ist ein Apartheid-Regime, für das es keinerlei Rechtfertigung gibt.“ Auch wenn diese Äußerung nicht intentional zur Diskreditierung benutzt wurde: Solche realitätsverzerrenden Phrasen tragen anti-israelisches Gedankengut in die Mitte der Gesellschaft und ihre Artikulation ist daher als besonders verantwortungslos zu beurteilen. 
staaten mit Kriegen überzieht und im Konflikt mit den Palästinensern die alleinige Schuld trägt. Die Rolle Israels wird dabei nicht nur auf die des Provokateurs und Störenfrieds im Nahen Osten, sondern in der Welt festgelegt.

„Jetzt auch noch die Schiffe vor dem Libanon zu provozieren. Vielleicht hat der Iranische Präsident doch eine gute Idee, wenn er Euch aus der Gegend vertreiben will.“[IBD_25.10.2006_ano_001]

„Hören Sie endlich auf, die Welt zu terrorisieren. Treten Sie endlich aus der ewigen Opferrolle heraus und stellen sich der eigenen Verbrechen. Sie besetzen unrechtmäßig zugesagte Gebiete, führen aktive, brutale und unverhältnismäßige Angriffskriege, glauben sich bei alledem im Recht und sehen einfach nicht ein, sich zum einen völlig zu isolieren und zum anderen einen kaum zu rettenden Konflikt zwischen den ihnen bislang wohlwollend zugewandten Staaten zu verursachen. [...] Israel bricht mal wieder die Welt in zwei.“[ZJD_31.07.2006_Wol_001]

Über den (oben beschriebenen) mentalen Elaborationsprozess, der auf dem Konzept des KOLLEKTIVEN JUDEN basiert, wird dem Zentralrat der Juden in Deutschland dann ebenfalls die Rolle global agierender Terroristen zugewiesen.

Extreme De-Realisierungen finden sich keineswegs nur bei Rechts- und Linksextremisten, sondern durchweg auch bei (sehr gebildeten) Schreibern aus der sozialen und politischen Mitte. Die Semantik der Entwertung, die durch Ausblendung, Verzerrung und Verfälschung von Informationen zustande kommt, ist ein gemeinsames Kennzeichen aller anti-israelisch argumentierenden Antisemiten (auch wenn sie sich als erklärte Anti-Antisemiten ausgeben). Vgl. hierzu (40), die E-Mail eines promovierten Sozialwissenschaftlers, der Israel mittels des Dämonisierungsvergleichs „hochgerüstetes Monster“ und des intertextuellen Verweises auf das Alte Testament als atavistisches, im moralisch überholten und verkommenen Judentum lokalisiertes Gebilde abwertet:

$$
\begin{aligned}
& \text { „Das ist sehr beschämend für den Staat Israel, der zu keinem wirklichen } \\
& \text { Frieden stark genug ist, sondern wie ein hochgerüstetes Monster agiert, } \\
& \text { dem alles Andere und alle Anderen unwichtig ist. Hass sät Hass, das } \\
& \text { heutige Israel ist im Blutschlamm des Alten Testaments stecken geblie- } \\
& \text { ben. Ich fürchte um seine Zukunft.“ [IBD_01.06.2010_Göl_001] }
\end{aligned}
$$

Während de-realisierende Sprachgebrauchsmuster von Extremisten aber primär mittels vulgär-aggressiver Beleidigungen und Beschimpfungen sowie expliziter judenfeindlicher Stereotypausdrücke artikuliert werden, kommunizieren gebil- 
dete Israelfeinde ihre Abneigung eher über Implikaturen als Moralappelle, Ratschläge und Aufforderungen und nehmen damit Israelis (und Juden) gegenüber eine ausgeprägt paternalistische Haltung ein (s. hierzu Kap.10.3). Ein typisches Beispiel für implizite Verurteilungen dieser Art ist die viel benutzte Floskel $^{35}$ von der „unverhältnismäßigen Gewalt“, die impliziert, es gebe keinen nachvollziehbaren Grund für den Einsatz des israelischen Militärs. Die Sprachproduzenten maßen sich also (trotz der Entfernung von über 4.000 Kilometern zum Krisengebiet, das sie strategisch bewerten) eine allwissende Beobachter- und Expertenposition an. Wenn es keine plausible und rechtfertigende Begründung für Gewaltanwendung gibt, so sind die naheliegendsten, darauf aufbauenden Implikaturen, dass die israelischen Streitkräfte Gewalt anwenden, weil sie es so gewöhnt sind, weil sie exzessive Militärschläge auch ohne Grund für sinnvoll halten und/oder weil sie (von Natur aus) gern gewalttätig sind. Diese Unterstellungen liefern mögliche Lesarten mit ausgeprägtem antisemitischen Assoziations- und Wirkungspotenzial. Auch Phrasen wie systematische Vernichtung, brutale Vorgehensweise und Krieg gegen die Zivilbevölkerung unterstellen qua Implikatur, Israels (Militär-) Politik sei ohne Not intentional destruktiv und ohne Weiteres zu vermeiden, wenn nur der gute Wille dafür da wäre. Das dominante Wortfeld bei der Bewertung der israelischen Militäraktionen, vor allem bei den Libanon- und Gaza-Einsätzen 2006 und 2009, hat das semantische Merkmal 'nicht den Relationen entsprechend' als Kern: Demgemäß finden sich in den Schreiben neben dem Wort unverhältnismäßig vor allem Lexeme wie unangemessen, übertrieben, überzogen, ungerechtfertigt, ungerecht, unfair, unanständig sowie mörderisch, rücksichtslos, brutal, barbarisch, erbarmungslos. Militäraktionen werden dabei bevorzugt als Mord(taten) referenzialisiert. Das zweite semantische Feld, das dominant in den E-Mails ist, betrifft die Opfer-Thematik. Neben Opfer (mit dem Zusatz israelischer Gewalt) werden Lexeme wie Leidtragende, Unschuldige, Unbeteiligte verwendet, um die unterstellte Unverhältnismäßigkeit ${ }^{36}$ der israelischen Militärpolitik hervorzuheben und zu betonen. Die konzeptuellen Bereiche MORD, UNVERHÄLTNIS-

35 Eine Kollokations- und Wortfeldanalyse (s. hierzu Kap. 2) zu einem aus 450.088 Wörtern (1.266 Seiten) bestehenden Teilkorpus aus digital vorliegenden Zuschriften aus dem Jahr 2006 an den ZJD und die IBD mit dem Programm antconc 3.2.1.0 ergab, dass das Lexem unverhältnismäßig eine zentrale Vokabel innerhalb israel-kritischer Zuschriften ist. Die Stichprobenanalyse ergab, dass 60 mal das attributiv oder prädikativ verwendete Adjektiv unverhältnismäßig benutzt wurde, 5 mal sein verneintes Antonym (nicht verhältnismäßig); das Nomen Unverhältnismäßigkeit tauchte 12 mal auf. Des Weiteren fanden sich 280 Mal QuasiSynonyme wie überzogen und unangemessen.

36 Die Verfasser bleiben dabei in der Regel eine Antwort schuldig, was ihrer Meinung nach ein „normales/angemessenes“ Maß für Militäraktionen gegen terroristische Angriffe und Raketenbeschuss wäre. 
MÄSSIGKEIT und ZIVILISTEN/UNSCHULDIGE werden also in ein argumentatives Verhältnis gebracht.

Die für anti-israelische Äußerungen typischen Kriterien Dämonisierung, Delegitimierung und Doppelstandard (unikaler Bewertungsmaßstab) und die sich aus ihnen ergebenden Argumente lassen sich nun vor dem Hintergrund der obigen Ausführungen als spezifische Formen der De-Realisierung subsumieren. Alle drei basieren auf einer judeophoben Konzeptualisierung, die ein Zerrbild Israels umfasst, und sie haben das Ziel, Israel als jüdischen Staat zu entwerten. Sie treten daher in der Regel kombiniert und semantisch-konzeptuell durch pseudo-kausale Relationen miteinander verknüpft auf.

\subsubsection{Mittel der Dämonisierung: „israel ist der teufel“}

Seit zweitausend Jahren gehört es zur Judenfeindschaft, dass Juden dämonisiert werden (s. Kap. 4). In der aktuellen Variante des Anti-Israelismus steht Israel im Fokus dieses tradierten Entwertungsprozesses. Judeophobe Dämonisierung stellt einen Prozess der extremen Aus- und Abgrenzung von Juden mittels irrationaler Negativbewertung dar. Die Dämonisierten werden als Personifizierung des Bösen oder als Weltenübel gesehen, das die Menschen heimsucht, sie erschreckt, bedroht und/oder ihnen Schaden zufügt.

(41) „ein total schlimmes volk ist das. israel ist der teufel. sorry aber so ist es.“ [ZJD_Gaza2009_60/816_Ste_001]

(42) „Die Israelis sind und bleiben, egal was sie der Welt auch vorgaukeln, die größten Rassisten, Kriegsverbrecher, Kriegstreiber, Mörder, Kindermörder, Menschenrechtsverletzer, Völkerrechtsverletzer, Folterer, Räuber und Diebe, Nazis, Lügner, Terroristen, Nichts und niemant hat mich bisher vom Gegenteil überezugen können. ${ }^{37}$ Und das wird auch in Zukunft nicht geschehen weil sich die Israelis nie ändern. Mit anderen Worten sie sind und bleiben verlogene Schweine. ...die Welt hasst sie.“ [IBD_04.12.2007_Dro_001]

37 Hier wird expressis verbis ausgedrückt, was kennzeichnend für eine antisemitische Einstellung ist: die obsessive Fixiertheit auf Juden und die unerschütterliche Resistenz gegenüber Fakten. Der Verfasser gibt selbst zu, was die meisten Judenfeinde leugnen: eine bestimmte, strikt festgelegte Konzeptualisierung als Glaubenssystem mit absolutem Wahrheitswert im Kopf zu haben, die unter keinen Umständen verändert werden soll. 
Die den Juden unterstellte Bösartigkeit ergibt sich in dieser Perspektive allein aus dem ureigenen Charakter bzw. der Natur der Dämonisierten, die per se und unveränderbar als schlecht gewertet werden. Das Konzept des EWIGEN JUDEN wird auf Israel projiziert, s. auch die Beispiele (50), (56) und (57); vgl. auch die folgende E-Mail einer Familie aus Berlin:

\begin{abstract}
„Mit Abscheu und tiefer Verachtung verfolgen wir in den Medien das Massaker Israels in Gaza und im Libanon. Die fadenscheinigen Begründungen für die massiven Angriffe auf zivile Ziele sind mehr als erbärmlich. Blickt man Jahrzehnte zurück, war es immer Israel, das anderen Land weggenommen, Städte zerstört und Orte dem Erdboden gleichgemacht hat. [...] In der ganzen Welt haben die Juden an Achtung und Vertrauen verloren.“[ZJD_30.07.2006_Ans_001]
\end{abstract}

Das Dämonisierte wird stets außerhalb der gesellschaftlichen Werte und ethischen Normen verortet, die die Basis für die (positive) Selbstbewertung der WirGruppe bilden (vgl. Befu 1999: 22f.).

(44) „Ihr seid Bestien, Teufel, Unholde!!!!“ [ZJD_27.12.2008_ano_003]

(45) „Und wir werden solang gegen Israel sein, bis Israel wieder auf den Weg der Menschen zurück gekommen ist.“ [IBD_08.07.2011_Wac_001]

Die Kontrastierung und absolute Entwertung erlauben es, die Dämonisierten bzw. das Dämonisierte ohne moralische Bedenken als (vermeintlichen) Zerstörer der Gemeinschaft zu verurteilen und seine Existenzberechtigung zu negieren.

(46) „Hallo ihr bluttriefenden Judenschweine! Ich bestreite ein Existenzrecht Israels und ein Lebensrecht der jüdischen Pestilenz.“

[IBD_26.04.2009_Kru_001]

(47) „Der Judenstaat Israel gleicht im Moment einer stinkenden Pestbeule, die ausgetrocknet werden muß.“ [IBD_10.08.2006_Mue_001]

Die wesentlichen Verbalindikatoren von Dämonisierung sind die Verwendung von pejorativen, das Referenzobjekt zumeist dehumanisierenden Lexemen, von negativen Hyperbeln und Metaphern sowie von NS-Vergleichen. ${ }^{38}$

38 Bei seriösen Kritikern findet man diese Verbalformen nicht. 


\section{Pejorative Lexik und Dehumanisierungen}

Dass die Verwendung pejorativer Lexeme wie Schweine, Schlächter, Verbrecher, Mörder, Monster oder Terroristen ein lange tradiertes Charakteristikum der verbalen Judenfeindschaft ist, haben wir bereits anhand der diversen aggressiven Sprachhandlungen, die gegen Juden gerichtet waren und sind, erörtert (s. Kap. 10).

(48) „Sie zeigen einmal mehr, dass Israelis Schweine sind. Sie brechen die Waffenruhe um die Libanesen und die Hisbollah zu provozieren, damit sie weiter Menschen abschlachten können.“ [IBD_20.08.2006_Dro_001]

(49) „Der Staat Israel benimmt sich in Gaza wie eine Nation von Schweinen.“ [ZJD_09.01.2009_Wol_001]

Beim Anti-Israelismus zeigt oft eine gruppenindizierende Komponente wie in dem Kompositum Judenschweine oder der Nominalphrase jüdische Verbrecher an, dass mit dem Sprechakt nicht nur die Diffamierung Israels, sondern aller Juden beabsichtigt wird. Semantisch explizit wird angezeigt, dass die Beleidigungen und Drohungen kollektiv judenfeindlich gemeint sind. Die umfassende Gruppenzugehörigkeit kann aber auch implizit vermittelt werden wie in (50):

„Ihr israelsichen schlächter, seit 2000 Jahren bringt ihr nur gewalt und krieg in die welt“ [IBD_30.3.2006_Sur_001]

Hier wird die Geschichte des jüdischen Volkes als „Beleg“ für die Verkommenheit der Israelis herangezogen und damit auf eine homogene Kategorie JUDEN zurückgegriffen. Vgl. entsprechend (51), wo jüdisches Volk und Israel in ein gemeinsames Konzept gefasst werden:

(51) „Es scheint so, das das jüdische Volk aus der Geschichte nichts gelernt hat und das was sie uns deutschen vorwerfen (3. Reich) nun in ähnlicher Form mit den Palästinensern machen, diese tagtäglich drangsalieren, bombardieren, mit Wasserknappheit bestrafen und so weiter.“ [IBD_05.06.2009_Jou_001]

Dehumanisierungen sind die häufigsten Formen der kollektiven Negierungen: Israel und seine Bevölkerung werden als Pestgeschwür, Unrat, Teufelswerk, Monster, Kontergan-Gebilde etc. bezeichnet: 

„Ihr seid einfach nur menschlicher Müll.“ [IBD_20.02.2009_Wei_001] „Widerwärtiges israelisches Pack, [...] Ihr Rattenpack.“ [IBD_05.05.2007_Kol_001]

Dehumanisierungen sind immer gleichzeitig auch Dämonisierungen, denn den Betroffenen menschliche Züge abzusprechen, ist eine extreme Form der Entwertung. Dämonisierungen gehen aber nicht notwendigerweise mit Dehumanisierung einher. Menschen können auch als (besonders schlechte, verkommene) Menschen aus der Wertegemeinschaft ausgegrenzt werden, ohne dass ihnen das Merkmal NICHT-MENSCHLICH zugeordnet wird.

(54) „Ihr Israelis seit doch allesamt nur erbärmliche wiederliche Möchtegerneopfer!!! Unmenschlich und Grausam gehen Sie gegen Hilfsschiffe vor....erbarmungslos töten sie Unschuldige Menschen [...]“ [IBD_01.06.2010_Rei_001]

Jede verbale Dämonisierung vollzieht semantisch eine extreme Negativbewertung und Ausgrenzung. Sie basiert also auf einer bilateralen Konzeptualisierung - einem Manichäismus -, die strikt zwischen gut und böse unterscheidet, wobei das Konzept des PRINZIPIELL ANDEREN maßgeblich ist.

Als „kollektiver Jude“ wird Israel zum Projektionsfeld judenfeindlicher Phantasien. Mehrfach ist in den Schreiben davon die Rede, die Israelis (,Jüdische Schlächter in Palästina“) seien „blutdürstig“ [IBD_22.07.2006_Ble_002]: In dieser metaphorischen Verwendung ist eine aktualisierte Übertragung des tradierten BLUTKULT-Stereotyps auf Israel zu sehen. Zahlreiche andere uralte Stereotype (JUDEN ALS LÜGNER, ALS HINTERHÄLTIGE BETRÜGER, ALS AUSBEUTER UND SCHÄDLINGE) werden auf den modernen Staat projiziert (s. Beispiele in Kap. 4). Die politische Diskreditierung erfolgt zumeist über die Zuschreibung von (angeblich typisch jüdischen) Charaktereigenschaften:

„Eure derzeitigen Provokationen [...] haben nur ein Ziel. Und dieses Ziel zeigt euren niederen Charakter und eure Hinterlistigkeit.“

[IBD_31.10.2006_ano_001]

Das mentale Bild des KOLLEKTIVEN JUDEN ISRAEL ${ }^{39}$ wird explizit durch generische Referenzialisierungen im Singular oder im Plural ausgedrückt (s. auch Kap. 6):

39 Alle semantischen Kategorisierungen und auf tradierten Stereotypen aufbauenden Argumente zeigen, dass beim Anti-Israelismus die alten Muster der Judenfeindschaft 
„Aber was macht der 'Jude' denn jetzt mit den Palästinensern? [...] hat der 'Jude' damals nichts gelernt?““[ZJD_Gaza2009_271/816_ano_001]

(57) „Dir Drecksjuden direkt eine in die Fresse. Du bist schuld am Elend dieser Welt!““[IBD_19.08.2008_Bau_001]

Während in (56) und (57) die Konzeptualisierung eines homogenen Wesens jüdischer Natur durch den typisierenden Singular aktiviert wird, geschieht dies in (58) und (59) mittels pluraler Referenz, die persönlich (durch die Anrede) oder distanziert verbalisiert werden kann:

„Die Juden in Israel gehen mit unvorstellbarer Brutalität vor.“ [ZJD_24.07.2009_Har_002]

$$
\text { „Ihr dreckigen Juden und MOERDERBANDE.“ [IBD_05.08.2010_ano_001] }
$$

Beide Formen führen $\mathrm{zu}$ einer semantischen Reduktion mit der kategorialen Lesart 'typisch für Juden'.

Dass israelische Belange und Handlungen als jüdisch kategorisiert werden, zeigen auch die konzeptuelle Gleichsetzung durch die Synonymverwendung von Juden/Israelis wie in (60) und die Zuordnungen von israelischer Staatsangehörigkeit wie in (61) sowie die Adressierungen von Schreiben an den ZJD, wenn es um Vorwürfe gegen die Politik Israels geht.

(60) „Das alles, müßte euch Israelis doch bekantvorkommen.“ [ZJD_18.02.2006_Bri_001]

(61) „[...] Völkermord, den eure Regierung und die Köpfe eurer Religion in Gaza begehen [...].“[ZJD_Gaza2009_14/816_ano_001]

Mittels Hyperbeln beschreiben die Verfasser israelische Aktivitäten als „die schlimmsten Massaker“, die „furchtbarsten Gräueltaten“, die „größten Ungerechtigkeiten“ und betonen dabei die Unikalität der unterstellten Bösartigkeit des „Verbrecher- und Unrechtsstaates“ sowie die moralische Verkommenheit seiner Bürger:

aktualisiert werden. Es ist keineswegs der Nahostkonflikt, wie z. B. Klug (2004: 237) es annimmt, der hier eine wesentliche Rolle spielt. Die Krisenberichterstattung über diesen Konflikt gibt lediglich den konkreten Anlass für die Projektionsprozesse. 
(62) „Ihr seid doch das Unterste was Gott der Menschheit antun konnte.“ [IBD_22.07.2006_ano_007]

Israel selbst wird als Staat ebenfalls bevorzugt mittels hyperbolischer Wendungen und Metaphern charakterisiert und so als das Böse schlechthin stigmatisiert:

(63) „Israel ist das größte Übel, das die Menschheit je hervorgebracht hat. Es wird höchste Zeit, daß der Iran seine Atombombe, die Israel ja längst hat, zur Einsatzreife bringt, und diese Krake Israel endgültig und auf Dauer vom Erdboden verschwindet und nie mehr auftaucht!“

[IBD_03.06.2010_Spe_001]

(64) „Das einzige rassistische Apartheidregime der Welt Israel ist die einzige Gefahr für Weltfrieden.“ [IBD_06.05.2009_Hai_002]

Der metaphorischen Konstruktion in (65) liegt die Konzeptkopplung ISRAEL ALS eIteRbeule zugrunde (s. hierzu auch Bsp. (47) zur Pestbeule):

„Israel ist die Eiterbeule im Nahen Osten!“

[ZJD_Gaza2009_87/816_May_001]

Auf diese Weise wird Israel als 'krankhafter, ekliger Auswuchs' charakterisiert. Man kann daraus folgern, dass der Verfasser von (65) das Existenzrecht Israels infrage stellen möchte, da es üblich ist, Eiterbeulen mit Hilfe einer entsprechenden medizinischen Behandlung auszukurieren oder sogar durch einen operativen Eingriff zu entfernen.

Bei manchen Verfassern kennt die Maßlosigkeit der dämonisierenden Übertreibungen keine Grenzen. Die extreme Irrationalität, die mit jeder De-Realisierung einhergeht, wird hierbei transparent:

(66) „Israel dort anzusiedeln war der größte Fehler der Neuzeit, sogar inklusive erster und zweiter Weltkrieg!“ [ZJD_Gaza2009_498/816_May_001]

(67) „Israel [...] Schlimmer als der Holocaust, falls es diesen überhaupt gegeben hat.“[ZJD_Gaza2009_153/816_Rie_001] 


\section{Rechts - Links - Mitte}

Bei aller Homogenität in Bezug auf dämonisierende Semantik und diskreditierende Argumentation über alle politischen Grenzen und Differenzen der Verfasser hinweg, lässt sich bei der Referenzialisierung in anti-israelischen Schreiben doch quantitativ und qualitativ ein Unterschied konstatieren: Rechtsorientierte und rechtsextremistische Verfasser lassen schon bei der Benennung „ihrer Feinde“ keinen Zweifel daran, dass es nicht nur die Israelis sind, sondern alle Juden, die sie meinen. Entsprechend findet sich kaum ein Schreiben, in dem nicht Israelis auch als Juden oder jüdisch bezeichnet ${ }^{40}$ werden. Linke und linksextremistische Sprachproduzenten dagegen benutzen bevorzugt das Lexem Zionisten (um zu verdeutlichen, dass sie gegen die Idee eines jüdischen Nationalstaates sind), oft in Verbindung mit dem Adjektiv faschistisch. Schreiber aus der Mitte, die sich als ehrbare Anti-Antisemiten darstellen und den Eindruck einer judenfeindlichen Einstellung vermeiden wollen, verwenden in der Mehrzahl das Lexem Israelis und verzichten damit auf eine direkte Zuordnung der Religion, kodieren aber implizit zahlreiche judeophobe Stereotype und adressieren ihre E-Mails öfter an den ZJD (statt an die IBD). Hinzu kommt bei diesen Schreibern meistens entweder die explizit formulierte Forderung an den Zentralrat in Deutschland, mehr für den Friedensprozess zu tun und Israel zu kritisieren:

„Sprechen sie klare Worte und distanzieren sie sich von diesem sinnlosen Morden.“ [ZJD_Gaza2009_582/816_Bac_001]

oder implizit mittels Aussagen, die Moralappelle darstellen, der Vorwurf, die Juden in Deutschland würden moralische Einsicht vermissen lassen (s. auch die Beispiele in Kap. 5):

„Es bedarf Mut zur Wahrhaftigkeit und ein paar Regungen echter Menschlichkeit.“[ZJD_29.12.2006_Glo_002]

Hierdurch entsteht eine kollektive Verantwortungserweiterung der Art, nicht nur die Israelis, auch die deutschen Juden seien maßgeblich verantwortlich für den Konflikt in der Region und könnten die Entscheidungen der israelischen Regierung beeinflussen. ${ }^{41}$ Entsprechend werden konkrete Vorschläge zur Lösung des Nahostkonflikts keineswegs nur der IBD unterbreitet, sondern auch dem ZJD:

40 Oft findet sich die Gleichsetzung bzw. Identifikation bereits in der Anrede: „Sehr geehrte Diplomaten Israels - sehr geehrte Juden!“ [IBD_22.12.2006_Mar_001]

41 Dies ist eine weitere Variante der de-realisierten Weltsicht von Antisemiten, die auf dem 
(70) „Fangen Sie endlich an, Religionsgemeinschaft zu sein und das oberste Prinzip aller Religionen zu praktizieren: Frieden!“

[ZJD_01.09.2006_Haf_001]

(71) „Schließt endlich Frieden und gebt das widerrechtlich angeeignete Land zurück.“[ZJD_13.04.2007_ano_001]

In vielen Schreiben wird eine Polarisierung betrieben: Jüdische Deutsche werden (nach bekannter Tradition) abgesondert und als israeltreuer, unkritischer Verein charakterisiert, der solidarisch nicht mit Deutschland, sondern allein mit Israel sei (s. hierzu Bsp. (13), (18) und (25) in Kap. 5.2).

Der Konflikt in Nahost wird zum Anlass ${ }^{42}$ genommen, lange gehegte Ressentiments zu aktivieren und als legitim zu deklarieren.

(72) „Hass und Verachtung aller Juden in der Welt ist euch gewiß.“ [IBD_23.07.2006_Hud_001, Postkarte]

(73) „Der einzig wahre Grund des Krieg des Apartheidregime in Israel gegen palästinensischer Zivilbevölkerung ist Mordlust der israelischen Rassisten.“[ZJD_Gaza2009_32/816_Hai_001]

(74) „Die Judenfrage muss gelöst werden.“[IBD_18.01.2009_ano_001]

Es ist klar, dass der Nahostkonflikt lediglich ein Katalysator für die anti-israelischen und antisemitischen Gefühle ist. Betrachtet man die lange Geschichte der Judenfeindschaft, so sieht man im Wandel der Zeit die emotionsintensivierende Rolle von jeweils aktuellen Krisen- und Konfliktsituationen. Wäre der Nahostkonflikt friedlich gelöst, würden womöglich andere Schuldzuweisungen gegenüber Israel konstruiert wie die Verantwortung für Umweltkatastrophen, die Erderwärmung, Risiken globaler Atompolitik etc.

Konzept der WELTWEITEN JÜDISCHEN ALLIANZ UND SOLIDARITÄT basiert.

42 Vgl. Kreis (2005: 29): „Nicht den unerreichbaren harten Antisemiten, sondern dem großen Publikum [...] des braven Mittelfeldes muß immer wieder deutlich gesagt werden, daß für Antisemitismus und dessen Ansteigen keine noch so kritisierbare Aktion Israels für verantwortlich erklärt werden kann. Nichts in der Welt (weder die gezielten Tötungen von Hamas-Führern noch die räuberischen Enteignungen von Land, noch die Zerstörung von Lebenszusammenhängen durch den 'Schutzzaun', noch irgendeine Form der Arroganz der Macht), keine Umweltverhältnisse sind für Eintreten oder Anwachsen von Antisemitismus verantwortlich. Verantwortlich ist immer nur derjenige, der einen derartigen 'Ismus' entwickelt und verstärkt.“ 
Der Verfasser von (75), ein Student, sieht in dem Streubombenabwurf der israelischen Armee die Bestätigung für die Verkommenheit aller Juden und leitet davon die „kausale Notwendigkeit“ des Holocausts ab:

$$
\begin{aligned}
& \text { „Zutiefst erschüttert lese ich heute dass von der israelischen Armee, } \\
& \text { nach dem Krieg, Streubomben auf den Südlibanon geworfen wurden. In } \\
& \text { den letzten Wochen habe ich Hitler begriffen warum er die Juden aus- } \\
& \text { rotten wollte! Ab heute sind die Juden auch meine Gegner,am besten ihr } \\
& \text { verschwindet als erstes aus Deutschland. Solche Kriegsverbrecher sind } \\
& \text { bei uns nicht erwünscht.“[ZJD_01.09.2006_Sch_002] }
\end{aligned}
$$

Vergangenheitsbezogen gibt (sich) dieser Schreiber (über die aktuelle Projektionsfläche Nahostkonflikt) eine tradierte judeophobe Erklärung für die NS-Verbrechen ('Juden sind aufgrund ihrer Verderbtheit selbst schuld, dass man sie ausrotten wollte und will') und gegenwarts- wie zukunftsbezogen eine Rechtfertigung für seinen persönlichen Judenhass. Eine ähnliche Argumentation bietet (76): „Ihr habt endlich euer wahres Gesicht gezeigt ! Jetzt kann ich A. H. verstehen. Denn ihr seid nicht besser.“[IBD_01.06.2010_ano_042]

Der Verfasser von (76) findet in den Taten der Israelis einen Grund, die Verantwortung für die von Deutschen begangenen Verbrechen an den Juden von sich zu weisen und sich von der Erinnerungskultur Deutschlands zu distanzieren. Diese Täter-Opfer-Umkehr-Strategie mit ihrer Schuldabwehr- und Entlastungsdimension ist in zahlreichen E-Mails zu konstatieren.

(77) „Wer nach 57 Jahren Frieden und Freiheit in unserem Lande noch immer stichelt und sucht, was er uns an Schlechten anhängen kann, ist mehr als gut beraten in seinem eigenen Land für Ordnung und Frieden zu sorgen.“[ZJD_07.06.2002_Bre_001]

$$
\begin{aligned}
& \text { „Solange also das israelitische Volk (ein Teil davon) Scharon seine } \\
& \text { Buldozer/Schlächter Politik weitermachen läßt, möchte ich nie wieder } \\
& \text { anklagende Reden über den Holocaust, inklusive des architektonisch } \\
& \text { superhäßlichem Denkmal hören.“[IBD_19.07.2006_Sch_003] }
\end{aligned}
$$

Dass durch die in solchen Beispielen enthaltene Analogie, welche die Militärschläge Israels mit dem Massenmord an den europäischen Juden auf eine Ebene setzt, eine de-realisierende Relativierung des Holocausts vorgenommen wird, 
vermögen auch die akademisch Gebildeten, die sich dieses Argumentes bedienen, nicht zu reflektieren.

\section{„Ihr jüdischen Nazis“: NS-Vergleiche als Mittel der Dämonisierung}

Um das Ausmaß israelischer Gewalt verbal höchstmöglich zu potenzieren, werden mit NS-Vergleichen irreale Kontrastierungen etabliert. Sie konstituieren absolute Täter-Opfer-Oppositionen.

(79) „Heute sind die wehrlosen und unschuldigen Palästinenser die Opfer der Nazi-Juden!“ [IBD_15.03.2007_Postkarte]

So findet sich auch bei nahezu allen Schreibern die Verwendung von (Juden und Israelis dämonisierenden und den Holocaust marginalisierenden) NS-Vergleichen in verschiedenen formalen und semantischen Varianten. ${ }^{43}$

Regierungsvertreter Israels werden mit Nazis verglichen oder gleichgesetzt:

(80) „Die israelische Regierung spricht wie die Nazis, sie handelt wie die Nazis - sie sind die Nazis des 21. Jahrhunderts.“

[IBD_02.05.2006_L_001, Postkarte]

(81) „Die Mörderbande unter dem Davidstern macht der SS unterm Hackenkreuz alle Ehre. Ein Ministerpräsident Olmert und eine Aussenministerin mit KZ-Aufseher Mentalität lehnen jede Waffenpasue ab.“ [ZJD_01.08.2006_ano_009]

Alle israelischen Bürger werden als Nazis beschimpft, die angeblich mit NaziMethoden agieren; ihnen wird eine (jüdische) Nazi-Mentalität attestiert:

„IHR NAZIS UND KZWAECHTER DER PALAESTINENSER. DRECKSJUDEN !!!!!!!!!!!!!!!!!!!!!!!!!!!!!!!!!!!!!!!!!!!!!!!!!!!!!!!!!!!!!!!“ ‘IBD_14.05.2010_ano_001]

(83) „Ihr seid die neuen NAZIS, killen provozieren, das könnt ihr gut!“ [IBD_25.10.2006_ano_002]

Selbst bei NS-Vergleichen finden manche der Schreiber noch Steigerungsmöglichkeiten:

43 S. hierzu auch Schwarz-Friesel (2007: 195-199) und Eitz/Stötzel (2009). 

„Ihr seid schlimmer als die Nazis!“ [IBD_16.01.2009_Mar_002]

Der gesamte Staat Israel wird entweder direkt mit dem Nazi-Regime gleichgesetzt oder über die Nennung von Namen bekannter NS-Verbrecher in Analogie zu ihm gesetzt (s. hierzu Kap. 6):

(86) „Hitler hat man überwunden - Israel leider noch nicht.“ [IBD_18.07.2006_Sta_001]

(87) „Adolf Hitler hätte seine helle Freude an den Faschistenkameraden in Israel!“ [ZJD_25.07.2006_Wag_001]

(88) „Die Enteignung und Venichtung der Palästinänser hätten auch Eichmann \& Co. nicht effektiver und menschenverachtender planen und ausführen können.“ [IBD_05.07.2006_Pue_001]

Aber auch jüdische Deutsche, in Stellvertretung für diese vor allem die Mitglieder des ZJD, werden zu Nazis deklariert (weil ihnen kollektiv Mitschuld an der Gewalt in Nahost zugesprochen wird). So befindet ein Publizist aus München, der Mitglied der Partei Die Linke ist:

$$
\begin{aligned}
& \text { „Also: Stoppen Sie Ihren gezielten Völkermord, Sie sind das Ebenbild der } \\
& \text { Verbrecher von Auschwitz und Buchenwald.“ } \\
& \text { [ZJD_Gaza2009_776/816_Sch_001] }
\end{aligned}
$$

Die Palästinenserpolitik wird expressis verbis als „israelischer Holocaust“ oder „Genozid“ bezeichnet.

$$
\text { „Jetzt betreibt Ihr den Holocaust!!“ [IBD_04.08.2006_Pun_001] }
$$

Implizit findet sich diese Analogie zur NS-Zeit mittels Aussagen und Fragen formuliert, wie in den E-Mails von zwei Akademikern aus Halle und Berlin:

(91) „Hier werden ganz schlimme Erinnerungen für uns Deutsche wach.“ [IBD_07.04.2007_Lie_001] ${ }^{44}$

44 In einer Äußerung wie (91) ist eine doppelte Täter-Opfer-Umkehr-Implikatur enthalten: Zum einen werden Israelis als Täter stigmatisiert, zum anderen werden die Deutschen (und 
„Erinnert Sie das nicht an die schlimme Zeit in Deutschland, in der Sie selbst Opfer waren?“ [ZJD_18.02.2006_Bri_001]

Juden erscheinen so (in der Täter-Opfer-Umkehr) als Tätervolk. Neben ihrer diskreditierenden Funktion dienen diese unangemessenen Vergleiche stets auch der Schuldaufrechnung (s. o.).

\subsubsection{Fokussierung, unikaler Bewertungsmaßstab und Delegitimierung}

Man muss sich beim Anti-Israelismus zwangsläufig die (über die textorientierte, kognitionslinguistische Analyse hinausgehende, den Gesamtkontext berücksichtigende) Frage stellen, warum ein kleines, demokratisches Land zum Weltenübel erklärt wird, das eine kritische Presse, ein unabhängiges Rechtssystem, eine frei gewählte Regierung und eine multikulturelle Bevölkerung hat, in dem Frauen gleichberechtigt sind und ihnen gesellschaftlich alle Möglichkeiten offen stehen, das liberal und offen im Umgang mit Homosexuellen ist und das korrupte und kriminelle Politiker vor Gericht stellt? Warum nicht Länder, in denen Frauen entmündigt, gedemütigt und gesteinigt und Homosexuelle umgebracht werden und in denen Kritik brutal unterdrückt wird; Länder, die Wahlen manipulieren oder gar nicht erst zulassen, die regelmäßig Massenvernichtungswaffen testen, um Nachbarländer zu bedrohen, während die Bevölkerung hungern muss, die kriminelle und korrupte Politiker gewähren lassen, während Regimekritiker bedroht, eingesperrt, misshandelt oder getötet werden, die Kinder zu Soldaten machen und Frauen Opfer von Massenvergewaltigungen werden lassen? Warum ist Israel das einzige Land der Erde, dem gegenüber sich ein „Ismus“ entwickelt hat (kein Anti-Chinaismus, kein Anti-Nordkoreaismus, kein Anti-Sudanismus), der extreme Ausmaße angenommen hat? Warum wird bei allen anderen Ländern zwischen Regierung und Bevölkerung unterschieden, während Israel als ganzes Land über die Taten Einzelner diskreditiert wird? Warum wird die Existenzberechtigung bei keinem anderen Land der Welt in Frage gestellt?

Israel sieht sich einer im Vergleich zu anderen Krisen- und Konfliktregionen quantitativ wie qualitativ unverhältnismäßigen Kritik ausgesetzt, die ein auffälliges Ausmaß von extremer Emotionalität besitzt. Bei keinem anderen Thema schlagen die Emotionen Hass, Wut und Empörung so hoch wie bei Debatten und Kontroversen um den israelisch-palästinensischen Nahostkonflikt, ist das Bedürfnis so groß, „Lösungsvorschläge“ und „gute Ratschläge“ zu erteilen, „Strafmaßnahmen“ zu verhängen. Wenn nun aber ohne jeden Zweifel Gewalt,

nicht die Juden) als Opfer der „schlimmen Erinnerungen“ in den Fokus gestellt. 
Menschenrechtsverletzungen und Konfliktaustragung in anderen Ländern wesentlich stärker ausgeprägt sind als in Israel, muss es einen anderen Grund für seine exzessive Verdammung und Verurteilung geben. Unsere Analysen legen als Grund nahe, dass Israel jüdisch ist und Juden seit Jahrhunderten Opfer von massiven Diffamierungskampagnen waren und sind.

Israel steht als jüdischer Staat im Fokus aller modernen Antisemiten. Eine Art Lupeneffekt ist zu konstatieren (Singling-Out), der Art, dass eine unikale Fokussierung und Bewertung stattfindet. Aufmerksamkeit und Kritik richten sich bei Personen mit einer anti-israelischen Einstellung allein und besonders heftig auf Israel und nicht auch auf andere kritikwürdige Krisen und Konflikte in der Welt. Die bereits erörterten Hyperbeln sind symptomatisch für diese Unikalitätsperspektive:

„Ihr Land ist [...] das mit Abstand schlimmste Übel auf der Welt [...].“ [IBD_25.10.2006_Sch_002]

Der Nahostkonflikt wird als herausragendes Krisengebiet aufgefasst, das in der Weltpolitik absolute Priorität hat und als besondere Gefahr für die übrige Menschheit stilisiert wird. Andere regionale oder globale Konflikte werden entweder ignoriert oder nicht mit dem gleichen Maß an Kritik bedacht. In der Forschung ist dies als Doppelstandard ${ }^{45}$ bezeichnet worden: Israel wird mit anderen Kriterien beurteilt, mit einem anderem Maßstab bewertet. ${ }^{46}$ Was bei jedem anderen Land der Welt z. B. als legitime Selbstverteidigung, Kampf gegen Terrorismus oder zum Teil nicht zu vermeidende Begleiterscheinungen im Kriegszustand bewertet würde, wird in Bezug auf Israel als „Beweis“ für dessen „Grausamkeit und Schlechtigkeit“ gesehen (s. o.). Dem israelischen Militär wird entsprechend unterstellt, seine Einsätze zielten intentional auf Opfer in der Zivilbevölkerung.

„Bomben mit einer derart gewaltigen Sprengkraft mitten in eine dicht
besiedelte Stadt abzufeuern, hat absolut nichts mehr mit legitimer
Gegenwehr zu tun. Da werden ganz bewusst zivile Opfer angestrebt. ...
Dieser Staat Israel ist eine SCHANDE für die gesamte ZIVILISIERTE Welt

45 Dieser Terminus ist jedoch ambig und seine Semantik gibt nicht an, dass es sich um eine einmalige Bewertung handelt. Wir bevorzugen daher „unikaler Bewertungsmaßstab“.

46 Es gab bislang noch nie Kommentare der Art „Syrien hat als Staat seine Existenzberechtigung verwirkt“ oder „das serbische Volk ist im Blutrausch“ oder „Nordkorea ist eine Schande für die Menschheit“ oder „Nazi-Methoden in China“. Gegenüber Israel sind solche Verbalexzesse an der Tagesordnung. 
und für alle, die noch einen klitzekleinen Funken Anstand haben. UND ICH BIN KEIN ANTISEMIT!“ [ZJD_Gaza2009_330/816_Gün_001]

Jeder tatsächliche oder angebliche Fehler Israels wird sofort benannt und dramatisch de-realisiert, jede Gewaltanwendung als besonders verwerflich und mutwillig böse interpretiert. So werden aus militärischen Aktionen infolge von Selbstverteidigungshandlungen ,kaltblütige Morde“:

\begin{abstract}
„Das brutale Vorgehen Ihrer Regierung gegen die FriedensaktivistInnen der Gaza Solidaritäts-Flotte erfüllt mich mit Entsetzen. Es schockiert mich, dass Ihr Land, dass sich als zivilisiert darstellt, diese Schiffe auf solch eine völkerrechtwidrige Weise gekapert und Menschen auf dem Schiff kaltblütig ermordet hat. Ich bin erschüttert, dass Menschen dafür sterben mussten, weil sie der Bevölkerung von Gaza Hilfe bringen und Hoffnung spenden wollten.“ [IBD_02.06.2010_Rat_001]
\end{abstract}

Es werden (zum Teil unerfüllbare) Erwartungen an Israel gestellt, die an kein anderes Land der Erde gestellt werden (z. B. die Forderung, auf Selbstverteidigung zu verzichten). Die in diesem Zusammenhang von Israel geforderte „besondere Verantwortung“ besteht dabei für viele vor allem darin, dass Gewalt gegen die eigene Bevölkerung hingenommen werden soll:

(96) „Der Ausweg wäre [...] Rückzug der Armee. Darauf folgen sicherlich Selbstmordattentate. Dann aber darf eben nicht zurückgeschlagen werden.“[ZJD_10.04.2002_Kut_001]

Sind auch objektiv betrachtet die militärischen Aktivitäten, Aufrüstungsbestrebungen und Menschenrechtsverletzungen in vielen (diktatorischen) Ländern wesentlich gravierender als in der Demokratie Israel (und würden daher weitaus berechtigter die Aufmerksamkeit von „Friedensaktivisten und Humanisten“ erhalten müssen), so gilt doch die ganze Konzentration Israel.

„ich protestiere [...] gegen die fortgesetzten und vorsätzlichen Vergehen gegen die Menschenrechte und die zahlreichen Verstösse gegen UN-Resolutionen, die der Staat Israel [...] in Palästina begeht und noch weiter begehen will.“ [IBD_29.03.2004_Sta_001]

Die unikale Fokussierung und Evaluation ist als unmittelbare Folge der de-realisierenden Dämonisierung zu sehen: Israel wird quasi zum ,Juden unter den Staaten der Welt“ (s. hierzu auch Grigat 2009) und damit Objekt exakt derglei- 
chen Diskriminierungs- und Diffamierungsmechanismen wie Juden schon seit Hunderten von Jahren. So wie Juden für Antisemiten das Übel der Menschheit sind, so ist Israel per se der schlimmste aller Staaten, ganz gleich, was er tut oder nicht tut (s. repräsentativ hierfür auch Bsp. (93)).

(98) „Die Gründung des Staates Israel ist der größte Fehler, der je von Menschen gemacht wurde.“ [IBD_03.03.2008_Moe_001]

$$
\text { „Der 3. Weltkrieg geht wohl von Israel aus!“ [IBD_02.06.2010_Bra_001] }
$$

Das Kriterium des anderen Maßstabs liegt auch vor, wenn wie in (100), (101) und (102), E-Mails von Akademikern, explizit oder implizit argumentiert wird, ausgerechnet „der Staat der Holocaustopfer“ dürfe nicht selbst zum „Tätervolk“ werden.

(100) „das jüdische Volk hat in den letzten Jahrzehnten und Jahrhunderten viel zu erleiden und zu erdulden gehabt.Vertreibung, Terror, Diffamierung, Völkermord. Müßte also nicht gerade das jüdische Volk Vorbild und Vorreiter in Nächstenliebe, Güte Großmut und Toleranz sein?“ [ZJD_07.04.2002_Pek_001]

(101) „Nach ihren eigenen schlimmen Erfahrungen eigentlich unfassbar.“ [IBD_30.11.2007_Rat_001]

(102) „Ist es nicht gerade Aufgabe des israelischen Volkes, nach den gemachten Erfahrungen andere Mittel als die Gewalt oder den Totschlag im Zusammenleben mit den Nachbarn anzuwenden?““[IBD_17.07.2006_Ley_001]

Die Geschichte hat bislang nicht gezeigt, dass leidvolle Erfahrung ein ganzes Volk kollektiv sensibler, besser (oder schlechter) macht und dies an folgende Generationen weitergibt. Trotzdem wird genau dies bei Israel aufgrund der Basis des homogenen Konzepts KOLLEKTIVER JUDE als Selbstverständlichkeit unterstellt. Hier werden pseudo-psychologische Zusammenhänge konstruiert, die der doppelten moralischen Verdammung von Israelis und Juden dienen: 'Sie sind verwerflich, weil sie Gewalt anwenden. Und dies, obgleich sie doch aufgrund ihrer leidvollen Geschichte gelernt haben und geläutert sein müssten. Das wiederum macht sie zu besonders schlechten Wesen.'

(103) „die Nachkommen der Opfer werden selbst zu unbeschreiblichen Tätern.“[ZJD_01.08.2006_Bah_001] 
„Ihre Solidaritätsbekundung zu der kriegerischen Offensive Ihrer Landsleute in Israel ist ein Hohn für die Opfer Ihrer Bomben im Libanon. Hat denn gerade ihr Volk nicht aus dem zweiten Weltkrieg gelernt??“ [ZJD_29.07.2006_Boe_001]

Die von den Schreibern konstatierte Unsensibilität gegenüber vergangener Leiderfahrung ergibt sich sinnvoll nur aus der unterstellten Lernunfähigkeit des ,jüdischen Volkes“ und dem Transfer dieses „moralischen Versagens“ auf den Staat Israel. Damit wird implizit eine konstante Charaktereigenschaft angenommen: 'Juden sind von Natur aus unverbesserlich schlecht.' Durch die Kontrastierung 'wir Deutschen haben sehr wohl etwas aus der Geschichte gelernt' wird diese Negativbewertung noch zusätzlich betont. ${ }^{47}$

Anti-israelisch eingestellte Personen belassen es oft nicht bei persönlicher verbaler Aggressivität, sondern sie suchen die Öffentlichkeit, versuchen, „Überzeugungsarbeit" zu leisten (und senden daher Kopien ihrer Schreiben an den ZJD und die IBD auch an Journalisten, Politiker und/oder die Bundesregierung und/ oder stellen sie ins Internet). Zudem fordern sie nonverbale Aktionen; insbesondere rufen sie oft zu Protest- und Boykotthandlungen gegenüber Israel auf, die sie als „notwendige Sanktionen“ bezeichnen.

„Deutsche, kauft keine israelischen Früchte.“ [IBD_10.08.2006_Neu_001]

(106) „Sie sind ein miserables, miserables Land. Ich werde für den Rest meines Lebens alles boykottieren was aus Israel kommt.“

[IBD_31.07.2006_Sch_008_Postkarte]

(107) „Ich hoffe die Deutschen boykottieren Israels Waren und kaufen keinerlei Waren mehr von diesem Land, bis Israel mal vernünftig handelt. Wir werden es so machen und haben auch unseren Urlaub in Israel abgesagt.“ [IBD_14.07.2006_Beh_001]

Dass solche Aktionen in der NS-Zeit gegen Juden usuell waren (und sprachlich nahezu strukturidentisch gefordert wurden) und welche Konsequenzen diese hatten, wird ausgeblendet oder als „legitim“ verteidigt. Boykottaufrufe werden in den Schreiben an den Zentralrat und die Botschaft bevorzugt von linksorientier-

47 Derselben Pseudo-Logik folgend müsste man dann unterstellen, dass die Deutschen aufgrund ihrer brutalen Vergangenheit besonders erfahren und prädestiniert für Gewaltanwendungen seien. Damit wäre dann das zu Recht zurückgewiesene Tätervolk-Konzept legitimiert. 
ten, sogenannten „Friedensaktivisten“ artikuliert. Es gibt ein prototypisches Argumentationsmuster in den Texten, das bis in die kleinsten sprachlichen Details hin homogen bei allen Boykottbefürwortern aus der bürgerlichen Mitte anzutreffen ist: Werden sie für ihre unangemessenen Vorschläge und Unterschriftenaktionen kritisiert, sehen sie sich „bösartig als Antisemiten verunglimpft“ und beklagen das angebliche Meinungsdiktat der „Antisemitismuskeule“; sie heben hervor, dass sie „jüdische Freunde haben“ und sich „dem Judentum verbunden“ fühlen, dass sie „Kishon lieben“ und „zu Klezmer-Konzerten“ gehen, dass sie von „prominenter jüdischer Seite Unterstützung“ finden. Die ostentative Parallele zu den antisemitischen Boykottaufrufen der Nationalsozialisten „vermögen“ sie „nicht zu erkennen“, vielmehr lasse es „ihr Gewissen nicht zu, tatenlos zuzusehen“. ${ }^{48}$

Auffällig ist, dass einige der Schreiber eine Wende bzw. einen Sinneswandel in ihrer Sicht auf Israel thematisieren, der „ihnen die Augen geöffnet“ habe, nachdem sie jahrelang durch die „gleichgeschaltete Presse“ und „feige Zurückhaltung der offiziellen Regierungskreise“ indoktriniert worden seien (s. hierzu auch die Beispiele (178) bis (181) in Kap. 5.2). Typisch hierfür sind (108), die E-Mail eines Professors aus Sachsen, und (109), die E-Mail eines linksorientierten Bürgers aus Berlin:

(108) „Ich hatte bis vor wenigen Jahren die deutsche Standard-Meinung zu Israel, aber seit den Kriegen im Libanon und Gaza, bei denen die Israelis unvorstellbar grausam vorgingen, habe ich viel über Israel nachgedacht. Ich glaube, viele Leute in Deutschland sind am Umdenken, und bald wird die Stimmung kippen.“[ZJD_24.07.2009_Har_001]

(109) „Glücklicherweise gibt es mit jeder israelischen Aggression mehr AntiZionisten vor allem auch in Deutschland und es bleibt zu hoffen, dass sich damit auch eine kritischere Grundhaltung gegenüber Juden in Deutschland allgemein durchsetzt.“[ZJD_15.08.2006_Moe_001]

Das „tabuisierte Thema“ müsse „zur Sprache kommen“, die „Fakten auf den Tisch gelegt“, das „Meinungsdiktat durchbrochen“, das „Schweigen beendet“" werden. ${ }^{49}$

48 Zuletzt fand dieses kommunikative Abwehr- und Legitimierungsmuster auch öffentlich in den Medien seinen Ausdruck: Der sozialdemokratische Oberbürgermeister in Jena glaubte, seinem „zerrissenen Herzen“ folgen zu müssen und war einer der Erstunterzeichner für einen von Pax Christi initiierten Boykottaufruf gegen Obst und Gemüse aus israelischen Siedlungen. Umgehend zollte inm die NPD dafür Beifall.

49 Günter Grass benutzte bei seiner Rechtfertigung nach massiver Kritik an seinem derealisierenden Text fast exakt die gleichen Floskeln. Im Gespräch mit dem Journalisten Tom Buhrow äußerte er am 05.04.2012: „Es muss endlich mal zur Sprache kommen. Aber was ich 
Ein ausgeprägter Missionarsdrang anti-israelischer Aktivisten ist Teil ihrer obsessiven Intoleranz: Antisemiten deklarieren ihre anti-israelischen Aussagen als „Meinungsfreiheit“ und fordern uneingeschränktes Rederecht. Ich fordere, ich verlange, ich bestehe auf meinem Recht etc. sind Floskeln, die viel in diesem Zusammenhang benutzt werden. Dieses Recht sprechen sie Menschen, die eine andere Meinung vertreten, jedoch ab, indem sie es als „Manipulation“ und „hasserfülltes Anti-Deutschtum“ bewerten. Auffällig ist hierbei der unbedingte Wahrheitsanspruch, der keine andere Sicht zulässt:

„Das ist Realität in Palästina. Das ist die Wahrheit!!“

[ZJD_11.03.2007_Mon_001]

Entsprechend beenden viele dieser Schreiber ihre E-Mails mit dem Appell an Zentralrat und Botschaft, ihre ,falsche Gesinnung“ zu überdenken und ,in der Hoffnung auf eine Änderung ihrer Ausrichtung und Werte“ [ZJD_01.09.2006_Tef_001].50

Jedes Gegenargument und jede Faktendarlegung, die ihrem Weltbild nicht entspricht, wird vehement und mit großer Polemik zurückgewiesen:

„Ich lasse mich nicht in die antisemitische Ecke stellen, das ist Meinungsfaschismus!“ [ZJD_04.03.2007_Mar_001]

Dies spiegelt sich in den E-Mails und Briefen (aber auch im Internet) darin wider, dass sowohl die Ergebnisse der Antisemitismusforschung diskreditiert werden (,gekauft“, „unwissenschaftlich“, „methodisch anfechtbar“, „von jüdischen Geldgebern in Auftrag gegeben“, „unseriöse Wissenschaft“") als auch Reportagen ${ }^{51}$ in den Massenmedien, die ein realistisches, ausgewogenes Bild des Nahostkonflikts zeichnen („nicht objektiv“, „voreingenommen“ etc.).

„Was soll das mit dem Antisemitismus. Wenn einer nur ein wenig Kritik an den Juden übt, ist er gleich ein Antisemit... Was ist aber mit den Juden,

dann erlebe, ist eine fast wie gleichgeschaltete Presse. Es kommen keine Gegenstimmen vor.“ 50 Der Verfasser hebt dabei in seiner E-Mail mehrmals hervor, er sei ein „sensibilisierter Bürger“: „Antisemitismus im Besonderen und der Ausgrenzung und Pauschalisierung gegenüber allen religiösen, ethnischen und individuellen Mitmenschen im Allgemeinen, bin ich gegenüber sehr sensibel und verpflichtet!“ [ZJD_01.09.2006_Tef_001]

51 Reaktionen auf eine Fernsehsendung des Hessischen Rundfunks machen dies deutlich: Da in dieser Reportage u. a. kritisch über anti-israelische Propaganda und Tatsachenfälschung bei einem angeblichen Tötungsdelikt an einem Kind berichtet wurde, erhielt die Redakteurin eine Reihe von Schmähbriefen, die sie des Verbreitens der Unwahrheit und der Manipulation bezichtigten. Wir danken Esther Schapira, dass sie uns diese Schreiben zur Verfügung stellte. 
die Tag täglich Verbrechen gegen das Palästinensische Volk ausüben... Dann darf man natürlich nichts sagen. Juden dürfen alles machen was sie wollen und alle müssen die Schnautze halten, sonst wird man als Antisemit beschimpft. Man wenn ich schon sowas lese, krieg isch'n Plack“ [Userkommentar im Internet zum Antisemitismusbericht der Expertenkommission 2012 auf shortnews-kommentare.de]

Emphatische und emotionsausdrückende Phrasen wie „Besorgnis erregend!“ sind nicht etwa Ausdruck der Betroffenheit angesichts rechtsradikaler Gewalttaten oder der erschreckenden Forschungsergebnisse zur Verbreitung von Antisemitismus in der bürgerlichen Mitte, sondern Empörungsinszenierungen bezüglich der Entlarvung scheinbarer Israel-Kritik als Antisemitismus. Alle Strategien, die zur Diffamierung von Juden benutzt werden, finden auch bei der Diskreditierung der Forschung und der Forscher(innen) ihre Anwendung: Übergeneralisierungen, Verfälschungen, Dekontextualisierungen von Forschungsergebnissen sind insbesondere im Internet in den Kommentarbereichen sowie auf Homepages stark verbreitet.

\section{Delegitimierung}

Aus der unikalen Be- bzw. Entwertung Israels ergibt sich (der pseudo-kausalen Logik von Antisemiten folgend) geradezu zwangsläufig die Delegitimierung des gesamten Staates Israel, denn ein Staat, der so abgrundtief böse und so gefährlich ist, so die Argumentation, hat in der zivilisierten Weltengemeinschaft keine Existenzberechtigung. Delegitimierung liegt vor, wenn das Existenzrecht Israels als Staat bezweifelt wird (was oft verbunden ist mit der Forderung, diesen Staat aufzulösen) und wenn ihm das Recht zur Selbstverteidigung abgesprochen wird.

„Seit Ausrufung eines jüdischen Staates vor 50 Jahren hat sich Israel noch nicht $\mathrm{zu}$ einer toleranten Demokratie entwickelt [...]. Jedenfalls haben Sie ihr Existenzrecht verwirkt.“[ZJD_12.04.2002_Ana_004]

Die meisten der Schreiber verfügen über keinerlei eigene, sichere, überprüfte Erfahrung und sind eigenen Angaben zufolge noch nie in Israel gewesen (haben also ihre Meinung ausschließlich über sekundäre Informationsquellen erhalten), vertreten aber ihren Standpunkt so vehement und hoch emotional, als seien sie selbst in Israel Opfer oder Augenzeuge von unvorstellbaren Brutalitäten gewesen (s. Kap. 9.2). Das Bedürfnis und die Bereitschaft, an die Verkommenheit Israels zu glauben, jede unterstellte Schlechtigkeit als wahr zu akzeptieren, muss bei 
diesen Personen sehr groß sein. Anti-israelisch eingestellte Personen sind daher nicht auf Ausgleich oder Vermittlung aus, sondern wollen die Auflösung bzw. radikale Veränderung des jüdischen Staates. Dies kann drastisch und vulgär umgangssprachlich ausgedrückt werden, wie in den Zuschriften von Rechtsextremisten, die ihre Forderung nach Vernichtung des jüdischen Staates fast immer auch an die Negierung des Existenzrechtes aller Juden koppeln (s. die Beispiele (46) und (47)) oder verbal-aggressiv und dämonisierend als (linksextremer) Antizionismus wie in (114):

„Die Errichtung des zionistischen Gebildes in Palästina gehört zu den großen Verbrechen der Menschheitsgeschichte, und das zionistische Gebilde genießt nicht das leiseste moralische Existenzrecht. Ich jedenfalls pflichte voll und ganz dem iranischen Präsidenten bei, wenn er sagt, der Zionismus sei eine Krankheit, und das zionistische Gebilde ein Unrechtsgebilde.“[IBD_16.07.2006_Tsc_001]

Typisch für gebildete Schreiber aus der Mitte, die Israel als Anachronismus, Anomalie oder Apartheidstaat bezeichnen, ist es dagegen, „zum Guten der Menschheit“, im „Sinne der Gerechtigkeit“ oder „im Interesse des Weltfriedens“ globale „Lösungsvorschläge“ (d.h. Auflösung oder Veränderung des jüdischen Staates) vorzutragen (die nicht immer realistisch sind):

(115) „Am Besten wäre die Verlegung von Israel auf deutschen Boden. Dann wäre der (deutsche nicht der jetzt israelische) Holocaust gesühnt und es kehrt endlich Ruhe in Nahost ein.“[ZJD_Gaza2009_498/816_May_001]

Argumente, die zur Delegitimierung von Israels staatlicher Existenz herangezogen werden, basieren auf einer Reihe von Bewertungsgrundlagen und pseudokausalen Begründungszusammenhängen (s. hierzu die bereits aufgeführten Beispiele unter Kap. 7.1.3 und 7.2.1).

Die rassistische Delegitimierung basiert auf dem Feindbild des EWIGEN JUDEN (mit den Stereotyp-Kombinationen AUSBEUTER, PARASITEN und HEIMATLOSE NOMADEN):

(116) „Nur durch die Auflösung des israelischen Staates kann das Zusammenrotten der Juden unterbunden werden und damit ihre hochgradig aggressiven Tendenzen als vereintes Volk, daß die Erbaggression und Erbfrustration hemmungslos auslebt. Die aus Israel ausgezogenen Juden haben dann die Möglichkeit, sich wieder woanders anzusiedeln. Die Juden waren schon zu Zeiten des alten Testaments ein Normadenvolk, das mal 
in Ägypten mal nach Babylon emigierte, letztes übrigens wegen moralischem Fehlverhalten, um dann wieder nach Israel zurückzuziehen.“ [ZJD_30.11.2006_Gel_001]

Die moralische Delegitimierung bezieht sich auf die unterstellte Gewalt gegenüber anderen arabischen Staaten (,Gräueltaten der israelischen Kriegsführung“) und den Palästinensern („unzivilisiertes Verhalten“, „unverhältnismäßige Gewalt“, „Staatsterror"):

„Aber ich akzeptiere nicht, dass die Politik Israels es in den Jahren seiner Existenz nicht verstanden hat, sich in einer fremden Region so zu assimilieren, dass dies ohne systematische Vernichtung (vor allem in jüngster Zeit) abgelaufen wäre.“[ZJD_15.08.2006_Ran_001]

(118) „Immer mehr wird klar, dass Israel der einzige Aggressor im Nahen Osten ist - es wird Zeit, dieses Problem einer Endlösung zuzuführen! Israel hat sein Existenzrecht bereits verspielt!“ [ZJD_15.08.2006_Moe_001]

Historische und politische Delegitimierung bezieht sich auf die Behauptungen, Israel sei ein Unrechtsstaat (s. die Apartheid-Vergleiche), dessen Gründung gegen das Völkerrecht verstoßen habe, Israel sei eine globale Gefahr für den Weltfrieden („aufgrund fortgesetzter Aggressivitäten“) und betreibe imperialistische Besatzungspolitik („Landraub und gesetzeswidrige Okkupation“):

(119) „Heute stelle ich fest: die Gründung des Staates Israel [...] war angesichts der gerade überwundenen Nazi-Gräuel nicht zu verhindern. Fest steht aber, dass diese Staatsgründung [...] eine völkerrechtswidrige Handlung war.“[ZJD_08.11.2007_Wen_001]

(120) „[...] Politik in Israel [...] Diese ist aber ebenso ungerecht wie die damalige Apartheid in Südafrika, und ich nehme an, dass sie ebensowenig Bestand haben wird.“ [ZJD_20.12.2009_Has_003]

In vielen Texten werden die drei Typen der Delegitimierungsargumentation miteinander kombiniert, wobei deren untrennbare Kopplung an die Dämonisierung Israels transparent wird:

(121) „Auf gestolenem land wurde ein historisches monster gezeugt, geboren und gemästet: Israel, die einzige Militär‘demokratie’ der welt!“ [IBD_15.05.2006_Bec_001] 
Als Konsequenz ergibt sich die Forderung, den Staat Israel zu reglementieren oder im Extremfall aufzulösen (zu den diversen „Lösungsvorschlägen“ s. Kap. 10.3). In diesen Forderungen drückt sich eine Position der vermeintlichen (kognitiven, emotionalen und moralischen) Überlegenheit und einer erforderlichen Belehrung von einem (paternalistischen) Standpunkt aus, der Israel kollektiv entmündigt und das Recht auf eigene Entscheidungen und Selbstbestimmung nimmt.

Respektverweigerung und Delegitimierung artikulieren sich kommunikativ auch durch die Weigerung, den Namen des Staates, den man ablehnt, zu benutzen. Während Rechtsextremisten bei der Referenz auf Israel bevorzugt Neologismen wie Israhell, IsraHölle und USrael sowie metaphorische Schimpfwörter wie KonterganStaat, Krüppel-Israel verwenden, bevorzugen Linke Bezeichnungen wie besetztes Gebiet, Territorium, Zionistenstaat und benutzen Verfasser aus der Mitte Paraphrasen wie Heiliges Land, das Land der Palästinenser oder die für das Territorium vor der Staatsgründung übliche Bezeichnung Palästina, um sprachlich zu indizieren, dass Israel von ihnen nicht akzeptiert wird. Da Namen eine wichtige identitätsstiftende Funktion haben und als Symbole repräsentativ für die Person bzw. das Land an sich stehen (s. Bering 2010), zielt die Stigmatisierung von Namen immer auf die gesamte Existenz des Kritisierten.

\section{3 "Wie ich gerade in meiner Tageszeitung las ... “ Intertextuelle Verweise und verbale Konvergenzen: Zum Wirkungspotenzial monoperspektivischer Nahostkonfliktberichterstattung}

Auffallend oft verweisen die Schreiber auf Berichte über den Nahostkonflikt, die sie in den Medien rezipiert haben.

„Herr Botschafter, ich habe gerade Radio gehört und frage Sie: Warum wundern Sie sich noch, daß so viele Menschen die Israelis hassen, wenn diese Besatzer tagtäglich die Palästinenser demütigen, quälen und ihre Lebensgrundlage zerstören?““[IBD_23.12.2005_Sch_001, Brief]

Solche intertextuellen Verweise ${ }^{52}$ auf massenmedial vermittelte Informationen in den Schreiben zeigen, dass viele Menschen bestimmte Krisenberichterstattungen zum Anlass nehmen, anti-israelische Meinungen zu artikulieren. Ob und

52 „Intertextualität“ bezeichnet die spezifische, intendierte und markierte Form der Bezugnahme von Texten auf andere Texte/Diskurse und Textmuster. Intertextuelle Verweise dienen generell der Legitimation der vom Schreiber vertretenen Position (s. hierzu Kap. 11.2). 
inwieweit sie zudem auch durch diese zum Teil monoperspektivischen Berichte und Kommentare beeinflusst worden sind, vermag eine textlinguistische Analyse nicht immer eindeutig zu eruieren. Man kann nur (angesichts der extrem emotionalen Reaktionen der Rezipienten, die dann als Produzenten ihrer Wut und Empörung Ausdruck verleihen) vermuten, dass es sich bei diesen Beiträgen um Konfliktberichterstattungen mit hohem Emotionspotenzial handelte. Teilweise geben die Verfasser aber auch detailliert Auskunft über ihre Quellen:

„Freitag, 3. 4., 23.00 Uhr, ZDF, Aspekte: Langer Bericht über Ihre Kriegsverbrechen in Gaza. Es läuft einem kalt den Rücken runter! Sie Schufte, Sie Kriegs-Verbrecher!“ [ZJD_27.12.2008_ano_001]

Viele Schreiber kopieren auch ganze Texte oder Textstellen in ihre E-Mails, um die eigene Argumentation zu bekräftigen und abzusichern. So legitimiert der Verfasser von (124) seine Äußerungen mit einem Spiegel-Newsticker, der den Tod von 20 libanesischen Zivilisten meldet. Der Newsticker wird unkommentiert als Vollzitat samt Quellenangabe in Form eines Hyperlinks angehängt:

„[...] Warum müssen auch unschuldige Menschen sterben? ... Unschuldige Zivilisten töten? Das geht zu weit! Der Staat Isreal stellt sich nicht besser, als die Angreifer der Hisbollah, wenn es so weitergeht! http:// www.spiegel.de/politik/ausland/0,1518,426884,00.html

Israels Luftwaffe beschießt Kleinbus - 20 Tote

Erneut fliegt Israels Luftwaffe heftige Angriffe im Libanon: Im Süden des Landes wurden laut libanesischen Sicherheitskreisen 20 Menschen getötet. Das Hauptquartier der Hisbollah in Beirut wurde zerstört. Auch im israelischen Tiberias am See Genezareth schlugen Raketen ein.“ [IBD_15.07.2006_Koh_001]

Der Verfasser von (125) fügt seiner anti-israelischen E-Mail einen Anhang bei, der aus fünf anti-israelischen Volltextzitaten samt Quellenangaben besteht. Diese Zitate bezeichnet er als „Denkanstöße“. Dadurch drückt der Verfasser aus, dass er die in den zitierten Texten manifestierte anti-israelische Einstellung teilt. Es liegt demnach eine bestätigende Integration vor und die Zitate sollen die feindseligen Äußerungen des Verfassers faktisch untermauern.

„DaunsereBundesregierungresisdentgegenalle Tatsachen,einschließlich UNO-Ermittlungen die verbrecherische zionistische Kriegsführung unterstützt, wird dem Ansehen unseres Deutschen Volkes international erheblicher Schaden zugefügt. [...] Anhang: Denkanstöße anderer Art !“ [Es 
folgen 5 anti-israelische Texte aus den Internetquellen www.medico.de und Kommunisten-online.de und mit den Angaben „Erst schießen, dann fragen (Junge Welt) Von Rüdiger Göbel“ und „Weißer Phosphor: Ist Gaza Testgelände für experimentelle Waffen? von Jonathan Cook 14.01.2009 ZNet“ ausgewiesene Texte.] [IBD_16.01.2009_ano_001]

Der Produzent von (126) führt das Volltextzitat einer dpa-Meldung mit dem Nebensatz „wie der nachfolgende Bericht wohl beweist“ expressis verbis als faktische Legitimation für seine Beschimpfung „Ihr seid die Terrorristen“ ein:

(126) „Sehr geehrte Damen und Herren, Ihr seid die Terrorristen, wie der nachfolgende Bericht wohl beweist. [...] Tel Aviv (dpa) - Israelische Soldaten haben die Öffentlichkeit mit Aussagen über wahlloses Töten von Zivilisten und mutwillige Zerstörung während des jüngsten Gaza-Kriegs schockiert.“[IBD_19.03.2009_See_001]

In den meisten Fällen werden aber nicht die gesamten Texte, sondern nur die jeweils relevanten Passagen zitiert bzw. nur die Teile, welche die eigene Position stützen; es handelt sich also um partielle, zum Teil auch dekontextualisierte Zitate. Ob der vielfach thematisierte Sinneswandel tatsächlich (und ausschließlich) durch Medienberichte verursacht wird bzw. wurde, wie der Verfasser von (127) es darstellt, können wir dabei nicht rekonstruieren:

„[...] die schrecklichen Bilder ihrer Gewalt im Fernsehen [...] Schämen Sie sich, für mich - der ich früher ein Freund Israels war - ist dieses Land gestorben.“[IBD_05.02.2009_Kel_001]

Inwieweit Tendenzen in der Berichterstattung deutscher Medien maßgeblich dazu beitragen, dass ein emotional und kognitiv verzerrtes Bild von Israel vermittelt wird und zum Teil antisemitischem Gedankengut Vorschub geleistet wird, ist seit einigen Jahren Gegenstand wissenschaftlicher (und journalistischer) Untersuchungen (s. hierzu u.a. Dichanz/Breidenbach 2001, Faber 2002, Jäger/Jäger 2002, Behrens 2003, Sahm 2006, Langenbucher/Yasin 2009, Schapira/Hafner 2010, Schwarz-Friesel 2012c und Beyer 2012 sowie ausführlich Beyer, in Arbeit). Eine Vergleichsanalyse zu Texten aus unserem E-Mail-Korpus und medialen Texten hat gezeigt, dass es bei diesen beiden Diskurstypen zahlreiche Konvergenzen zwischen den Ausdrucksformen von israelfeindlichen Konzeptualisierungen gibt (s. hierzu auch Beyer/Leuschner 2010). Die von uns im Korpus konstatierte Häufigkeit der Verwendung des Lexems unverhältnismäßig spiegelt z. B. offensichtlich den starken Einfluss der Medienberichterstattung auf die Schrei- 
ber wider. Für den englischen Sprachraum ${ }^{53}$ ist die Dominanz des Vorwurfs der Unverhältnismäßigkeit bereits von Kalb und Saivetz (2007: 49-52) herausgestellt worden:

„there appears to be little doubt that the media everywhere emphasized the theme of 'disproportionality' from the opening day of the conflict, as though nothing else measured up to it in importance.“ (Kalb/Saivetz 2007: 49)

Als repräsentatives Beispiel dafür, wie im massenmedialen Kommunikationsraum durch einen extrem unsensiblen Sprachgebrauch Klischees bedient werden, die prototypisch für den antisemitischen Diskurs sind, sollen hier Äußerungen aus einem Transkript zur Talkshow Hart aber fair: Blutige Trümmer in Gaza - wie weit geht unsere Solidarität mit Israel? vom 21.01.2009, in der es um den Nahostkonflikt ging, genannt werden: Im Laufe dieser Fernsehsendung setzte der Journalist Ulrich Kienzle zunächst Israelis und Juden gleich bzw. nivellierte die notwendige Differenzierung, unterstellte ihnen Friedensunwilligkeit und verstärkte dieses Klischee noch zusätzlich, indem er den deutschen Staatsbürger Michel Friedman mit einer impliziten Schuldzuweisung ansprach (wobei dadurch das klassische judeophobe Stereotyp DEUTSCHE JUDEN ALS NICHT-DEUTSCHE bzW. ALS ISRAELIS kodiert wurde).

(128) Kienzle: „Es ist leider die Wahrheit: Wir müssen mal wirklich zum Konflikt zurückgehen. Die Ursache hatte einen ganz simplen Grund. Die Israelis oder die Juden oder wie auch immer wir es nennen wollen, haben die Palästinenser vertrieben. [...] Es geht um die Ursache des Konfliktes 1947, und damals wurden sie vertrieben und Sie [an Friedman gerichtet, d. Verf.] lassen sie nicht zurück.“

Die Ursachen des Nahostkonflikts wurden zudem historisch verzerrt sowie monokausal eingeengt und einseitig schuldzuweisend dargestellt: Statt auf den dann erfolgten Hinweis Friedmans, der mit der Richtigstellung, er sei deutscher Staatsbürger, die Unsinnigkeit der vorherigen Aussage klar macht, selbstkritisch $\mathrm{zu}$ reagieren, den Lapsus zu erkennen und diesen umgehend zu revidieren, verstärkt Kienzle seine klischeebelastete Argumentation noch mit der Behauptung „aber manchmal wirken Sie wie ein israelischer Propagandist“. Obgleich Friedman die Absurdität auch dieses Vorwurfs gegen ihn transparent macht, vermag sich

53 Hove (2008: 159 ff.) hat gezeigt, wie die Berichterstattung über den Beginn der Zweiten Intifada im norwegischen Fernsehen durch Auslassungen und Verfälschungen so gestaltet war, dass Israel einseitig und de-realisiert als Aggressor dargestellt wurde. Trotz wiederholter Anfragen und Faktendarlegungen verweigerte die Sendungsleitung jeden Kommentar dazu. 
der Journalist aus dem gängigen judeophoben Deutungsschema nicht zu lösen: „Jetzt kommen Sie mit der alten Antisemitismus-Keule.“

Das persuasive, meinungsbestimmende und -lenkende Potenzial von sprachlichen Strukturen und ihre vorurteilsbildende und ressentimentverstärkende Funktion werden bei solchen Äußerungen ignoriert oder marginalisiert, vielleicht auch aus populistisch-journalistischen Gründen in Kauf genommen. Beiträge dieser Art aktivieren und reaktivieren über israelfeindliche und derealisierende Sprachgebrauchsmuster tradierte Stereotype des judenfeindlichen Diskurses auch im öffentlichen Kommunikationsraum ${ }^{54}$ der Gesamtgesellschaft. „Die Wende [...] zu evidenten, öffentlich via Medien sichtbaren Ereignissen öffnet das Tor zur politischen Mitte“ (Bergmann/Heitmeyer 2005b: 234; s. hierzu auch Schwarz-Friesel 2009b).

In vielen Pressetexten zum Nahostkonflikt findet sich seit Jahren eine extreme, auf intensive Gefühle setzende Kontrastierung und Polarisierung zwischen Palästinensern und Israelis: Die Palästinenser werden oft als schwach, unterlegen, leidend und hilflos dargestellt; es überwiegen idyllische Landschaftsschilderungen. Im Kontrast dazu werden die Israelis (fast ausschließlich vertreten durch Militärangehörige oder Nationalreligiöse) als überlegen, stark und als High-Tech-Macht mit absoluter Kontrollgewalt referenzialisiert. Bei LexemAnalysen ${ }^{55}$ zeigt sich, dass bei der Darstellung der Israelis die Verben kontrollieren, zerstören, angreifen, schicken, befehlen, konfiszieren dominant sind, bei der Beschreibung der Palästinenser dagegen die Verben leiden, träumen, vertrieben worden sein, sterben; nominale Lexeme stammen vor allem aus den Wortfeldern Familie sowie Felder/Bauern, emotionsbezeichnende und -ausdrückende Adjektive sind traurig, ohnmächtig, wütend, unerträglich, hoffnungslos, schwach.

Wenn das Elend und die Verzweiflung der Palästinenser betont, aber nicht die Trauer und die Angst von Israelis erwähnt werden, wenn Aktionen der Armee ohne Nennung von Gründen als willkürlich dargestellt und pauschale TäterOpfer-Strukturen konstruiert werden, wenn Israel als übermächtiger Aggressor skizziert wird, liegt eine monoperspektivierte Berichterstattung ${ }^{56}$ mit einem

54 S. hierzu auch Braune (2010), der auf der Basis einer Korpusanalyse zu Leserbriefen in der Presse der Mitte zeigen konnte, dass zunehmend, unzensiert und ohne kritischen Kommentar der Redaktion, auch antisemitische Kommentare publiziert werden.

55 Diese Analysen basieren auf einem Korpus von über 500 medialen Texten (aus der Mainstreampresse) zum Nahostkonflikt, die anlässlich des Libanon- und Gaza-Konflikts 2006 publiziert wurden.

56 Vereinzelt wird diese einseitige Berichterstattung zu Ungunsten Israels auch in den E-Mails kritisch angesprochen. Seit 2010 sind vermehrt Schreiben zu konstatieren, in denen die Verfasser ihren Unmut über die anti-israelischen Medienberichte artikulieren. Vgl.: „Sehr geehrte Damen und Herren, wieder einmal wurde eine Schreckensnachricht verbreitet: Mit 
hohen Emotionspotenzial vor, die anti-israelische Bewertungen gekoppelt an intensive Gefühlswerte vermitteln kann (s. Schwarz-Friesel 2007: 222-230). Die möglichen Wirkungen einer so gestalteten Berichterstattung spiegeln sich dann in Äußerungen wie (129), (130) und (131) (sowie in den oben geschilderten Umfrageergebnissen zum Israelbild der Deutschen) wider:

(129) „Zu meiner Verwunderung musste ich feststellen, dass auch ich eine geistige Veränderung durch gemacht habe, von einem Freund der Juden zu einem Gegner. Ich bin nicht dem Braunen Mopp zuzuordnen sondern eher dem Liberalen Teil unserer deutschen Bevölkerung, und dieser Tatbestand beunruhigt mich am meisten. Ich hätte mit vor Wochen nicht vorstellen können solch einen Wandel durch zumachen. Die Bilder von den vielen unschuldigen Toten Kindern, Alten und Kranken Menschen die von der Israelischen Armee getötet wurden haben dazu beigetragen.“ [ZJD_01.08.2006_Wei_001]

\author{
„Betreff: Der Spiegel 35/08 Seite 13257 \\ Lese gerade im aktuellen Spiegel über Ihre Schweinereien in Palästina. \\ Schande über alle Juden! [...] Was ich tun kann: Alles Jüdische wird kon- \\ sequent boykottiert!“ [ZJD_26.08.2008_ano_001]
}

\footnotetext{
ernster Miene verkündete die Sprecherin, dass (sinngemäß) Israel wieder einmal zugeschlagen und einen Angriff auf Gaza gestartet habe. Die involvierte Nachricht von den Raketen aus Gaza wirkte wie ein lapidarer Appendix. Die Art der Nachricht, die Darstellung, die Mimik, die schlecht zurückgehaltene Entrüstung sorgt intuitiv für antiisraelische Stimmung. Wochenlang vorher haben wir von den Angriffen der Terroristen auf der anderen Seite offiziell so gut wie nichts gehört. Nun ist wieder das Opfer der Täter, auf den man zeigen darf. 'Selber schuld. Warum verteidigt ihr euch ...!'. Da Israel eine Demokratie ist, in der verheimlichte Untaten wie bei uns sofort ans Licht kommen und in breiter Öffentlichkeit diskutiert werden, kann die nachfolgende Dokumentation nicht unglaubwürdig sein. Ich möchte sie Ihnen nicht vorenthalten. Über 'Ärztepfusch' wird so oft berichtet - wie wär's mal mit einer Recherche über 'Medien- oder Journalistenpfusch'? Halbwahrheiten sind immer auch halbe Lügen ...“ [IBD_12.03.2012_Kau_001]

57 Dass im Spiegel auffallend oft brachiale Verbalismen zu verzeichnen sind, wenn es um die Charakterisierung von Israel und Israelis geht, hat bereits Behrens (2003) gezeigt. Unsere Analysen konnten diesen Eindruck bestätigen: Spiegel-Artikel zu Israel zeichnen sich oft durch den Gebrauch von intensiv evaluierenden Hyperbeln und Metaphern aus und die Referenzialisierungen von Israel weisen eine sensationalistische und überdramatisierende Tendenz auf.
} 
„Die schrecklichen Bilder bestätigen wieder einmal, dass der Judenstaat aus und mit Terror geboren wurde und er deswegen offenbar dazu verdammt ist, immerfort neuen Terror zu gebären.“

[ZJD_Gaza2009_5/816_Stö_001]

\section{Fazit}

Aufgrund der gesellschaftlichen Ächtung und Sanktionierung explizit antisemitischer Äußerungen haben sich indirekte Verbalisierungsformen für die Darstellung und Verbreitung judenfeindlichen Gedankengutes entwickelt, die u.a. über die Referenz auf Israel als „Kritik“ deklariert und als „Meinungsfreiheit“ legitimiert werden (und auf diese Weise bereits auf allen Ebenen des öffentlichen Diskurses zu verzeichnen sind). Die Analyse der Inhalte und der verbalen Mittel dieser Äußerungen aber macht transparent, dass diese Formen der sprachlichen Diffamierung nichts mit legitimer Israel-Kritik gemeinsam haben. Israel-Kritik und Anti-Israelismus lassen sich sprach- und kognitionswissenschaftlich klar und präzise mittels diverser Klassifikationskriterien als zwei verschiedene Typen von Texten bzw. kommunikativen Handlungen voneinander abgrenzen.

Bei der Beschreibung von Israel fällt bei anti-israelischen Texten vor allem die De-Realisierung auf, d.h. eine verzerrte, realitätsabgehobene Darstellung in Form von Falschaussagen und/oder durch Ausblendung von Fakten und/oder durch hyperbolische Dämonisierungen. Die pejorativen Lexeme, Hyperbeln und Metaphern in den israelfeindlichen Texten geben ein verzerrtes Bild des Staates und diffamieren kollektiv nicht nur seine Bürger, sondern mittels allgemeiner Schuld- und Verantwortungszuweisungen in der Regel auch alle Juden. Aus der Dämonisierung des jüdischen Staates folgen argumentativ Muster der unikalen Bewertung und der Delegitimierung. Wenn Israel, der jüdische Staat, als einmalig böse und verkommen an den Pranger gestellt wird (während wesentlich schlimmere Vergehen, Fehler und Verbrechen von andern Staaten gar keine oder kaum Erwähnung finden), schließt sich der konzeptuelle Kreis zur Judenfeindschaft: Israel steht im Mittelpunkt der aggressiven Attacken, weil es ein genuines Symbol des aktuellen jüdischen Lebens ist. Die Sprachgebrauchsmuster, die benutzt werden, um Israel zu stigmatisieren, entsprechen insgesamt exakt den Mitteln und Strategien, die seit Jahrhunderten bei der Diskriminierung von Juden Anwendung gefunden haben. Sowohl argumentativ als auch grammatisch-lexikalisch unterscheiden sich die kommunikativen Handlungen von Antisemitismus und Anti-Israelismus nicht. Daher ergibt sich durch die empirisch gestützten Textanalysen als Resultat die Bestätigung, dass Anti-Israelismus als eine moderne Formvariante der alten Judenfeindschaft $\mathrm{zu}$ betrachten 
ist. Hass und Wut konzentrieren sich auf den jüdischen Staat, der als kollektiver Jude konzeptualisiert wird. Lediglich die Leugnungs-, Rechtfertigungs- und Legitimierungsstrategien von Antisemiten aus der bürgerlichen und gebildeten Mitte markieren eine Differenz gegenüber dem manifesten Antisemitismus von Rechtsradikalen. Die Selbsterklärungen der Verfasser, es handele sich um den Ausdruck von moralischer Empörung und Sorge, täuschen jedoch nicht darüber hinweg, dass hier ein tief empfundenes Ressentiment verbalisiert wird. Entsprechend sind die Beteuerungen, „keineswegs antisemitisch, sondern nur israelkritisch eingestellt zu sein“, lediglich kommunikative Ablenkungsmanöver, die dem Schutz vor Sanktionen und Gesichtsverlust sowie der Selbstlegitimierung dienen. Abgesehen davon, dass anti-israelische Äußerungen (selbst wenn sie zum Teil tatsächlich nicht intentional antisemitisch artikuliert werden) nicht nur unangemessen, sprachunsensibel und unverantwortlich sind, da sie das Potenzial haben, über Inferenzen, Generalisierungen und Assoziationen ${ }^{58}$ antisemitische Ressentiments zu aktivieren bzw. re-aktivieren, konstruieren sie ein irreales Zerrbild, in dem Israel realitätsenthoben zum Aggressor stilisiert wird. Israel, das wichtigste moderne Symbol jüdischen Lebens, mit NS-Vergleichen zu diffamieren und argumentativ durch Feindbildrhetorik und anti-jüdisch assoziierte Topoi zu stigmatisieren, birgt eine weitere Gefahr: Durch diese Sprachgebrauchspraxis wird die Basis für die Verstärkung antisemitischer Ressentiments in der gesamten Bevölkerung ${ }^{59}$ etabliert und intensiviert.

58 Da Israel das bekannteste Symbol für jüdisches Leben darstellt und als jüdischer Staat konzeptualisiert wird, ergibt sich bei jedem anti-israelischen Text automatisch eine mentale Relation zwischen den Konzepten JUdEnTUM und ISRAEL. Die Assoziationsrelation 'israelischjüdisch' kann kognitionslinguistisch als usuell und prozessual betrachtet als automatisiert angesehen werden.

59 Dies zeigen die am Anfang des Kapitels skizzierten Umfrageergebnisse sowie die Flut an Tausenden von antisemitischen Kommentaren und Hassparolen im Internet anlässlich der Debatte um das anti-israelische Gedicht von Günter Grass. Die IBD erhielt binnen weniger Tage eine große Menge an Schreiben zu diesem Text. Wir konnten diese jedoch bis zur Fertigstellung des hier vorliegenden Buches nicht mehr analysieren. 